UNIVERSIDADE DE BRASÍLIA - UNB

FACULDADE DE ECONOMIA, AdMINISTRAÇÃo, CONTABILIDAdE E CIÊNCIA DA INFORMAÇÃO E DOCUMENTAÇÃO (FACE)

Programa de Pós-Graduação em Administração - PPGA

SÉRGIO EMÍDIO dE AZEVÊDo CAMPOS

COMPETÊNCIAS GERENCIAIS RELEVANTES ÀS ATIVIDADES-MEIO DE UMA INSTITUIÇÃO FEDERAL DE ENSINO SUPERIOR NO CONTEXTO DE MODERNIZAÇÃO DO ESTADO BRASILEIRO 
SÉRGIo EMídIo dE AZEVÊDo CAMPOS

\section{COMPETÊNCIAS GERENCIAIS RELEVANTES ÀS ATIVIDADES-MEIO DE UMA INSTITUIÇÃO FEDERAL DE ENSINO SUPERIOR NO CONTEXTO DE MODERNIZAÇÃO DO ESTADO BRASILEIRO}

Monografia apresentada ao Programa de PósGraduação em Administração (PPGA) da Faculdade de Economia, Administração, Contabilidade e Ciência da Informação e Documentação (FACE), da Universidade de Brasília, como requisito parcial à obtenção do grau de Especialista em Gestão de Pessoas.

Orientadora: Prof ${ }^{\mathrm{a}}$ Dra. Catarina Cecília Odelius 


\section{SUMÁRIO}

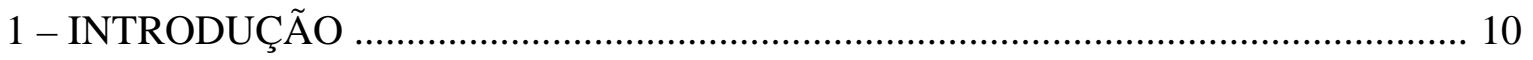

1.1 - Formulação do problema de pesquisa …………………………………….... 11

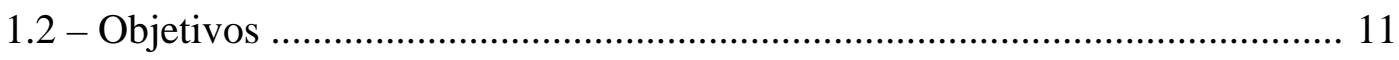

1.2.1 - Objetivo Geral .............................................................................. 11

1.2.2 - Objetivos Específicos .................................................................... 11

1.3 - Justificativas ………………………………………………………….... 12

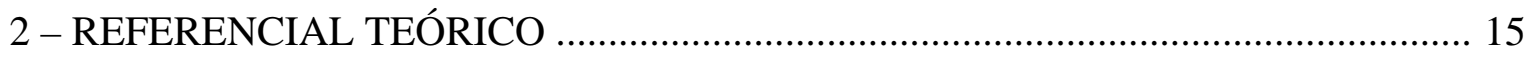

2.1 - Contextualização histórica ....................................................................... 15

2.2 - Competências individuais ou humanas .......................................................... 16

2.3 - Competência organizacional ......................................................................... 22

2.4 - Relação entre competência e desempenho competente .................................... 23

2.5 - Competências gerenciais .............................................................................. 27

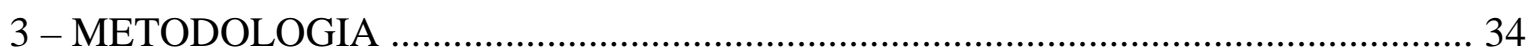

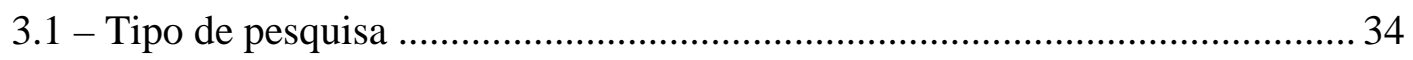

3.2 - População e Amostra ................................................................................. 35

3.3 - Instrumento …………………………………………………………... 36

3.4 - Procedimentos de coleta de dados ............................................................... 38

3.5 - Análise dos dados ...................................................................................... 38

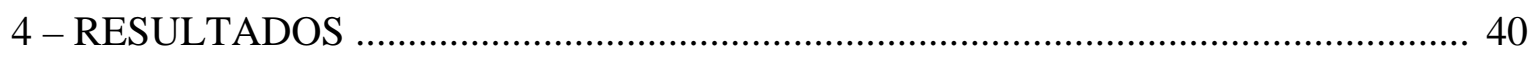

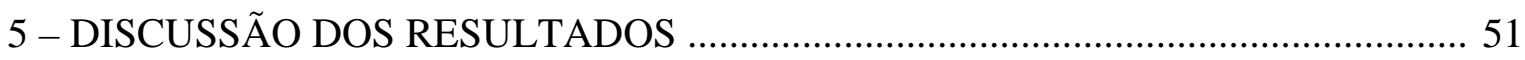

6 - CONSIDERAÇÕES FINAIS ................................................................................. 55

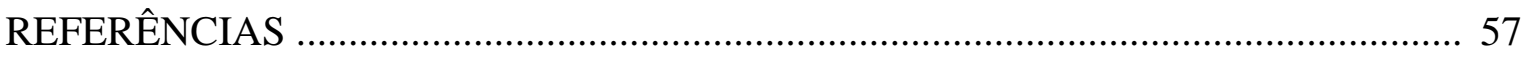

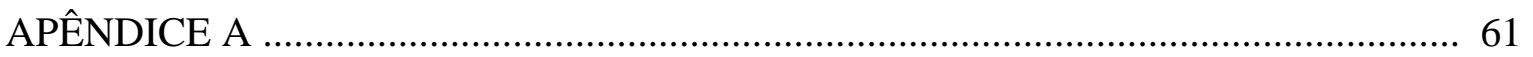


A todas as pessoas, gerentes ou não, cujo trabalho é imprescindível aos interesses das organizações e que acreditam que a ousadia e o erro são caminhos para as grandes realizações. 


\section{AGRADECIMENTOS}

Primeiramente a Deus, por ter me proporcionado, por meio de sua bondade infinita, as condições e o potencial necessários para concretizar mais uma vitória em minha vida.

Aos meus pais, José Campos (em memória) e Zilda Maria, que sempre me incentivaram a estudar e pela educação dos filhos, diante de todas as adversidades.

Aos meus irmãos, em especial a Simone Cristine (em memória), pelo convívio harmonioso e pela união nos momentos difíceis.

À minha querida esposa Carmem Luiza e aos meus adorados filhos Ana Luiza e Luiz Felipe, pelo imenso carinho, amor incondicional, compreensão, apoio e paciência com que conseguiram entender as horas subtraídas em seu convívio quando dos momentos de estudo.

À Secretaria de Recursos Humanos (SRH) da Universidade de Brasília (UnB), pela concessão de uma bolsa integral que possibilitou a realização do curso.

À minha orientadora, professora Doutora Catarina Cecília Odelius, pelos conhecimentos transmitidos e pelo auxílio dedicado que tanto me ajudaram a crescer pessoal e profissionalmente.

À coordenadora do curso, professora Doutora Maria de Fátima Bruno-Faria, pela dedicação imensurável, pelos auxílios sempre relevantes, pela paciência e transmissão dos conhecimentos extremamente necessários à conclusão desta monografia.

Aos meus colegas de curso, em especial a Laene, Emilly e Mariana, pela agradável convivência nos momentos compartilhados entre estudos e troca de experiências, sem os quais a conclusão deste trabalho se tornaria mais difícil.

A todos os gerentes que participaram da entrevista, pelas contribuições nas coletas de dados, sem as quais não seria possível concluir este trabalho no prazo estimado.

A todas as pessoas que direta ou indiretamente contribuíram para que este trabalho fosse realizado. 
“Gerentes não gerenciam, diretores não dirigem, compradores não compram e vendedores não vendem. Quem faz as coisas acontecerem são as pessoas de carne e osso, não cargos, títulos ou postos organizacionais.”

(Jack Welch)

"Já ancorado na Antártida, ouvi ruídos que pareciam de fritura. Pensei: será que até aqui existem chineses fritando pastéis?

Eram cristais de água doce congelada que faziam aquele som quando entravam em contado com a água salgada. O efeito visual era belíssimo. Pensei em fotografar, mas falei pra mim mesmo:

- 'Calma você terá muito tempo para isso... '

Nos 367 dias que se seguiram, o fenômeno não se repetiu. Algumas oportunidades são únicas.” 


\section{RESUMO}

Diante das exigências trazidas pela globalização nas últimas décadas do século $\mathrm{XX}$, as organizações foram obrigadas a buscar o crescimento constante para continuarem acompanhando as tendências do mercado, onde o homem é visto como elemento principal de todo e qualquer processo de mudança nas relações de trabalho e de modernização das organizações. Nesse contexto, muitas empresas começaram a repensar a gestão das competências, onde as tradicionais práticas de treinamento e desenvolvimento parecem não responder às novas demandas do mercado. A administração pública tem procurado acompanhar essas tendências por meio de ações voltadas para a reforma do Estado brasileiro na tentativa de reestruturar e modernizar a máquina administrativa, identificando as competências dos seus servidores a partir das terminologias desenvolvidas no setor privado. Assim, este trabalho teve como principal objetivo elaborar um mapeamento de competências gerenciais mais adequadas à natureza das atividades desenvolvidas pelos gerentes para que contribuam para o alcance dos resultados organizacionais em uma Instituição Federal de Ensino Superior no contexto de modernização do Estado brasileiro. O referencial teórico abordou as competências individuais e organizacionais, focando em competências gerenciais. O levantamento de dados abrangeu análise documental e entrevistas, realizadas com o uso de roteiro semi-estruturado. Tendo em vista a experiência do autor em vários anos de serviços dedicados à instituição em estudo, as entrevistas foram realizadas individualmente com dezoito gerentes, selecionados entre os que possuíam maior conhecimento da estratégia, da missão, dos valores, dos processos e da cultura da organização, visando ao mapeamento de competências gerenciais. Os dados foram submetidos à análise de conteúdo e foi verificada a freqüência com que foram mencionados. Concluiu-se que as competências apontadas pelos gerentes pesquisados são semelhantes às competências gerenciais delimitadas pela administração pública federal, e que eles consideram deter essas competências em parâmetros que consideram satisfatórios, se levados em consideração o contexto e as condições oferecidas aos gestores públicos.

Palavras-chave: Competências, competências gerenciais; competências organizacionais; competências humanas. 


\section{LISTA DE FIGURAS}

Figura 1 - Competências como fonte e valor para o indivíduo e para a organização ........ 18

Figura 2 - As três dimensões da competência .............................................................. 19

Figura 3 - Analogia entre as proposições de Pestalozzi, Bloom et al. e Durand .............. 20

Figura 4 - Modelo de gestão de desempenho baseada nas competências .......................... 22

Figura 5 - Condições necessárias ao desempenho competente ........................................ 25

Figura 6 - Identificação do gap (ou lacuna) de competências ......................................... 26 


\section{LISTA DE QUADROS}

Quadro 1 - Papéis e funções dos gerentes................................................................. 28

Quadro 2 - Competências gerenciais ........................................................................... 29

Quadro 3 - Processos e principais características do trabalho gerencial ......................... 30

Quadro 4 - Competências profissionais requeridas ......................................................... 32

Quadro 5 - Competências gerenciais sugeridas ............................................................... 52 


\section{LISTA DE TABELAS}

Tabela 1 - Nível hierárquico e função dos respondentes ............................................. 40

Tabela 2 - Competências informados pelos respondentes na questão 1 .......................... 42

Tabela 3 - Competências informados pelos respondentes na questão 2 ........................... 44

Tabela 4 - Competências apontados pelos respondentes na questão 3 ............................. 46

Tabela 5 - Competências não informados nas questões 1 e 2 e apontados na questão 3 .. 48

Tabela 6 - Comparação entre competências das questões 1 e 2 com a questão 3 .............. 50 


\section{1 - Introdução}

As últimas três décadas têm sido marcadas por um crescente interesse do Estado em identificar as qualificações e competências dos servidores públicos, a partir de terminologias desenvolvidas no setor privado. Em resposta ao processo de globalização, os gestores públicos (federal, estadual e municipal), têm focado o interesse em conhecer a importância da aplicabilidade dessas terminologias na solução de problemas enfrentados pelos gerentes de Recursos Humanos (RH), que tem crescido com as constantes reformas da administração pública em todo o mundo (BRESSER PEREIRA, 1999).

No Brasil, a administração pública passou por três grandes reformas na tentativa de reestruturar e modernizar a máquina do Estado. A primeira, a Reforma Burocrática de 1936, ditada segundo as regras descritas por Weber; a segunda foi sistematizada no Decreto-Lei 200, de 1967, por Hélio Beltrão. Ambas foram idealizadas e implementadas em contextos de ditadura política e sem debate com a sociedade. A terceira, iniciada em 1995, foi a primeira a pensar o setor público do país em um contexto democrático, com ênfase para o atendimento dos seus cidadãos, e com a consideração de que as instituições públicas devem ser eficientes e eficazes e o debate do Estado com a sociedade deve ser incrementado (BRESSER PEREIRA, 1999; FERREIRA, 1999).

Entretanto, tem sido um grande desafio para os governantes e para a sociedade o estabelecimento de políticas públicas em busca de alternativas que venham a contribuir para a implementação de programas permanentes de capacitação dos servidores que atenda ao Estado, às organizações, aos trabalhadores, aos consumidores e, principalmente, ao cidadão principal cliente do Estado.

Segundo Fleury e Fleury (2001), somente nos últimos anos o tema “competência” entrou para a pauta das discussões acadêmicas e empresariais, associado a diferentes níveis de compreensão: da pessoa (a competência do indivíduo), das organizações (as core competences) e dos países (sistemas educacionais e formação de competências).

Nesse contexto, a aceleração das inovações tecnológicas, a globalização da economia e a eficiência dos sistemas de comunicação têm provocado significativas turbulências nos ambientes organizacionais. Como conseqüência, as empresas têm enfrentado o aumento da competitividade, fazendo-as rever constantemente suas estratégias, suas formas de organização do trabalho e levando-as a buscar profissionais cada vez mais qualificados e com competências essenciais para cada função. Para as pessoas, uma das conseqüências tem sido a 
busca pelo aprendizado contínuo, que lhes propicie o desenvolvimento de novas competências e por contextos organizacionais que lhes favoreçam a aplicação dessas competências.

A questão é tratada por Carvalho (2003), da seguinte forma:

[...] um dos dilemas a ser enfrentado no século XXI, é o da sociedade centrada no crescimento sem emprego. As tentativas de explicar e de resolver esse dilema apontam consensualmente para a qualidade da formação profissional, uma vez que $o$ pressuposto é de que os empregos que agora são criados tendem a exigir um aumento de qualificações (CARVALHO, 2003, p. 67).

Assim, na busca da eficiência e da eficácia, muitas organizações têm centrado a atenção nas pessoas, preconizando, assim, a busca de uma nova relação entre a empresa e os indivíduos, baseada na participação, no comprometimento e no contínuo aperfeiçoamento profissional. Nesse sentido, os dirigentes têm se apoiado nos conceitos de competência para assegurar que os conhecimentos, habilidades e atitudes de seus colaboradores fiquem alinhados com a ação estratégica da organização.

\subsection{Formulação do problema de pesquisa}

Quais competências são necessárias para que os gerentes contribuam para o alcance dos resultados organizacionais em uma Instituição Federal de Ensino Superior no contexto de modernização do Estado brasileiro?

\subsection{Objetivos}

\subsubsection{Objetivo Geral}

O objetivo geral desta monografia é identificar as competências gerenciais necessárias para que os gerentes contribuam para o alcance dos resultados organizacionais em uma Instituição Federal de Ensino Superior no contexto de modernização do Estado brasileiro.

\subsubsection{Objetivos Específicos}

Como objetivos específicos, pretende-se nesta monografia:

i. Analisar, caracterizar e discutir os conceitos de competências;

ii. Comparar as competências identificadas com as encontradas na revisão de literatura;

iii. Listar as competências requeridas para a atuação das gerências;

iv. Elaborar um painel com as competências gerenciais mais adequadas para a natureza das atividades gerenciais estudadas. 


\subsection{Justificativa}

As últimas décadas do século XX foram marcadas por rápidas e vertiginosas mudanças tecnológicas, econômicas e sociais que transformaram o mundo do trabalho, das empresas e, conseqüentemente, das pessoas. Essa época foi marcada por uma epidemia de projeções e previsões sobre os futuros acontecimentos do século XXI, onde a gestão das empresas foi fundamental na reformulação do ambiente dos negócios, das novas configurações organizacionais e do perfil do gestor frente a essas transformações (RUAS, 2000).

Diante das exigências trazidas pela globalização, as organizações foram obrigadas a buscar o crescimento para continuarem competindo no mercado, onde o homem é visto como elemento principal de todo e qualquer processo de mudança nas relações de trabalho e de modernização nas organizações. Esse novo modelo de gestão aponta uma ênfase maior nas pessoas como recurso determinante do sucesso organizacional, uma vez que a acirrada competitividade leva as empresas a buscarem profissionais cada vez mais capacitados, aptos a enfrentar as ameaças e a identificar as oportunidades de mercado (BRANDÃO; GUIMARÃES, 2001).

Nas organizações governamentais, por uma questão de adaptação ao momento de transformação, ocorreram mudanças significativas nas formas de trabalho, onde foram abolidas tradicionais e conservadoras práticas até então implementadas para dar lugar a novas e modernas tecnologias e estruturas organizacionais, tais como os sistemas integrados de dados (SIAFI, SIAPE, SIASG) ${ }^{1}$ e a instituição das agências reguladoras dos serviços públicos (ANATEL, ANEEL; ANAC, ANP, ANS) ${ }^{2}$, criadas para adequar a organização e os profissionais aos ambientes turbulentos como os dos dias atuais.

Um dos assuntos que mais chamou a atenção no início deste século foi a perspectiva das competências do administrador público frente a um ambiente em constante transformação. Segundo Ruas (2000, p. 2), “foram muitas as páginas dedicadas ao administrador, estabelecendo, em seu conjunto, um amplo debate acerca das competências ‘necessárias' ao

\footnotetext{
1 SIAFI: Sistema Integrado de Administração Financeira; SIAPE: Sistema Integrado de Administração de Recursos Humanos; SIASG: Sistema integrado de Administração de Serviços Gerais.

2 ANATEL: Agência Nacional de Telecomunicações; ANEEL: Agência Nacional de Energia Elétrica; ANAC: Agência Nacional de Aviação Civil; ANP: Agência Nacional do Petróleo, Gás Natural e Biocombustíveis; ANS: Agência Nacional de Saúde Suplementar.
} 
gestor a fim de conduzir a organização a um bom desempenho, num ambiente instável e em transformação”.

Mesmo havendo muitos estudos sobre o trabalho do administrador (RUAS, 2000), ainda há lacunas a serem preenchidas, principalmente nas organizações públicas, onde muitos profissionais foram admitidos sem os critérios mínimos exigidos para exercer satisfatoriamente as atividades do cargo para o qual foram contratados. Contribui também para essa situação a dificuldade dos gestores em promover ações de TD\&E para desenvolver nos gerentes as competências essenciais às funções em que estão investidos. Os conhecimentos, habilidades e atitudes necessários a cada atividade só passaram a ser efetivamente levados em consideração com o advento da nova Constituição Federal de 1988. Na ocasião, o Estado estabeleceu a obrigatoriedade de concurso público de provas e de provas e títulos como único acesso ao serviço público federal, buscando no mercado os mais qualificados e, assim, valorizando a força de trabalho e melhorando a qualidade do serviço público a partir de novos modelos de gestão.

Segundo De Masi (1999), a ciência organizacional foi a que mais contribuiu para o progresso humano no século XX. Com o seu desenvolvimento, foi possível o fortalecimento de cada atividade, cognitiva e operacional, numa dimensão inexistente em todas as épocas anteriores da história, dentro e fora das organizações (DE MASI, 1999, p. 184).

Para De Masi (1999), o management foi o grande responsável pela alavancagem dos empreendimentos no século XX. Ele trata a situação da seguinte forma:

Foi o management que introduziu as novas tecnologias nos locais de trabalho, nas casas, nas diversões. Foi o management que criou as empresas-rede, as multinacionais, os distritos industriais, a globalização da economia, dos gostos, do consumo. Bem ou mal, os homens da organização mudaram o mundo no século XX muito mais do que os políticos, os padres, os militares ou os juristas (DE MASI, 1999, p. 185).

Nessa perspectiva, os órgãos públicos federais, como é o caso da instituição em estudo, têm sido obrigados a cumprir as exigências das políticas públicas implementadas pelo governo federal visando ao cumprimento de programas voltados para as finalidades de cada órgão. Tem sido cada vez mais forte a pressão dos órgãos federais de controle para que os objetivos institucionais sejam alcançados. A maioria dos órgãos públicos federais não tem conseguido atender às exigências dos planos, programas e projetos, bem como ao cumprimento dos prazos estabelecidos pelas políticas públicas (PACHECO, 1999). O fato de ainda existirem profissionais que foram admitidos no serviço público sem atender o disposto 
na Constituição Federal de 1988, faz com que seja importante identificar as competências gerenciais relacionadas com a modernização do aparelho do Estado brasileiro.

Seguindo essa tendência, quando das discussões da reforma do Estado em 1995, envolvendo membros de altos escalões da administração pública federal, a capacitação dos servidores públicos, voltada para a modernização do aparelho estatal, foi tratada por Pacheco (1999); Marconi (1999) e Bresser Pereira (1999), como primordial para a profissionalização do serviço público visando à sua aproximação ao setor privado quanto à qualificação e remuneração profissionais.

Assim, se faz necessária a identificação de competências atuais de uma instituição de ensino superior, comparando-as com as exigidas para as funções, o que servirá para subsidiar o desenvolvimento de ações visando a melhoria do desempenho na execução das tarefas e elaboração dos processos para cumprimento dos objetivos organizacionais, bem como servir de referência para o desenvolvimento de competências em organizações afins. 


\section{2 - Referencial Teórico}

A literatura sobre o assunto não mostra um consenso entre os autores que tratam de definição de competências, encontrando-se vários significados, sob várias perspectivas. Por isso, estruturou-se este trabalho da seguinte forma: primeiramente, faz-se um esboço sobre a contextualização histórica para se ter uma noção do assunto em estudo; em seguida, trata-se das competências individuais ou humanas; as competências organizacionais são tratadas em um terceiro momento; em seguida faz-se uma comparação entre competências e desempenho competente e, por último são abordadas as competências gerenciais.

\section{1 - Contextualização histórica}

No final do século XV, com o fim da Idade Média e início da Idade Moderna, a expressão competência era associada essencialmente à linguagem jurídica e correspondia à faculdade, atribuída ao indivíduo ou a alguma instituição, para analisar e julgar determinadas situações. Assim, competência veio a designar o reconhecimento social da capacidade do indivíduo se manifestar sobre determinadas questões e, mais recentemente, o termo passou a ser usado também para capacitar alguém a realizar uma determinada tarefa (ISAMBERTJAMATI apud BRANDÃO; GUIMARÃES, 2001, p. 9).

A partir do século XVIII, com o advento da revolução industrial, que se estendeu durante todo o século XIX e início do século XX, e o surgimento da administração científica de Taylor, cuja ênfase era aumentar a eficiência da indústria por meio da racionalização do trabalho do operário, a palavra competência foi incorporada à linguagem organizacional, passando a ser utilizada para qualificar a pessoa capaz de desempenhar eficientemente determinada tarefa (CARBONE et al., 2005). Nessa época, o conceito de qualificação proporcionava as condições necessárias para se trabalhar a relação profissional indivíduoorganização (FLEURY; FLEURY, 2000).

Entretanto, somente a partir da década de 1970 o interesse da academia pelo assunto passou a estimular as discussões teóricas e a realização de pesquisas nas organizações (CARBONE et al., 2005).

Nos anos de 1990, a terminologia competência, já conhecida no repertório da lingüística e das ciências psicológicas de matriz comportamental, é utilizada no vocabulário das organizações produtivas em um momento marcado pelo desenvolvimento das políticas de 
emprego orientadas pela busca de flexibilidade nas empresas e mudanças organizacionais na gestão de pessoas. Percebida como um estoque de recursos que o indivíduo detém, essa terminologia tem sido reconhecida pelas organizações produtivas e instituições educacionais como substituta da noção de qualificação profissional ancorada nos postos de trabalho (FLEURY; FLEURY, 2001).

Assim, na visão de Fleury e Fleury (2000, p. 18-19), “competência é uma palavra do senso comum e o seu conceito só revela seu poder heurístico, quando aprendido no contexto de transformações do mundo do trabalho, quer seja nas empresas, quer seja nas sociedades”.

\section{2 - Competências individuais (ou humanas)}

Para Fleury e Fleury (2001), o conceito de competência vem sofrendo mutações em decorrência de fatores como os processos de reestruturação produtiva, da intensificação das descontinuidades e imprevisibilidades das situações econômicas, organizacionais e de mercado e as sensíveis mudanças nas características do mercado de trabalho e das relações de trabalho, resultantes dos processos de globalização.

Essas mudanças podem ser administradas, mas exercerão impacto sobre as empresas, de maneiras diferentes, que deverão permanecer atentas às transações internacionais e às alianças temporárias, encarar a velocidade como uma questão importante e reavaliar o modelo empresarial usado para atender às exigências da nova economia (PRAHALAD, 1999).

Como afirma Perrenoud (1999), os profissionais estão constantemente sendo confrontados a situações mais ou menos novas, para as quais sentimos necessidade de encontrar soluções.

\footnotetext{
A vida coloca-nos, com maior ou menor freqüência, conforme nossa idade e condição e, também, em virtude de nossas escolhas, frente a situações novas, que procuramos dominar sem reinventar completamente a pólvora, lançando mão de nossas aquisições e experiências, entre a inovação e a repetição. Boa parte de nossas condições de existência é desse tipo. Com efeito, nossa vida não é tão estereotipada para que, a cada dia, tenhamos exatamente os mesmos gestos para fazer, as mesmas decisões para tomar, os mesmos problemas para resolver. Ao mesmo tempo, não é tão anárquica ou mutante que devamos, constantemente, reinventar tudo. A vida humana encontra um equilíbrio, o qual varia de uma pessoa ou fase do ciclo de vida para outra, entre as respostas rotineiras para situações semelhantes e as respostas a serem construídas para enfrentar obstáculos novos. (PERRENOUD, 1999, p. 28-29)
}

Perrenoud (1999, p. 7), define competência como “a capacidade de agir eficazmente em um determinado tipo de situação, apoiada em conhecimentos, mas sem limitar-se a eles”. 
Assim, para que uma situação seja tratada da melhor forma possível, é preciso colocar em prática e em sinergia vários recursos cognitivos complementares, entre os quais estão os conhecimentos (PERRENOUD, 1999).

As competências - que são expressas por meio de ações - "não são, em si, conhecimentos; elas utilizam, integram, ou mobilizam tais conhecimentos” (PERRENOUD, 1999, p. 8). Conhecimentos “[...] são representações da realidade, que construímos e armazenamos ao sabor de nossa experiência e de nossa formação” (PERRENOUD, 1999, p.7).

No entendimento de Le Boterf (2003), a competência não reside apenas nos recursos (saberes, conhecimentos, capacidades, habilidades) a serem mobilizados, mas na própria mobilização e combinação desses recursos, pois as ações competentes resultam desse saber combinatório.

Com relação aos recursos disponíveis, para Perrenoud (2001), a competência pode ser compreendida como:

[...] a capacidade de um indivíduo de mobilizar o todo ou parte de seus recursos cognitivos e afetivos para enfrentar uma família de situações complexas, o que exige a conceituação precisa desses recursos, das relações que devem ser estabelecidas entre eles e da natureza do "saber mobilizar". Pensar em termos de competência significaria, portanto, pensar a sinergia, a orquestração de recursos cognitivos e afetivos diversos para enfrentar um conjunto de situações que apresentam analogia de estrutura (PERRENOUD, 2001, p. 21).

Para Zarifian (1996; 2001), competência é o ato de assumir responsabilidades diante de situações profissionais que exigem complexidades diversas na execução de determinada tarefa. Uma ação competente é produto de uma combinação de múltiplos recursos pessoais. Segundo esse autor, a competência de um profissional reside no saber mobilizar e aplicar eficazmente os recursos pessoais para alcançar propósitos de trabalho. Nesse sentido, o conceito de competência tem uma função de adjetivo da ação e se assemelha ao de eficácia do desempenho (ZARIFIAN, 1996).

Segundo Brandão (1999), a competência é o resultado ou efeito da aplicação de qualificações do indivíduo no trabalho, sendo esse resultado o próprio desempenho do indivíduo no trabalho, que representaria a sua própria competência ou uma medida desta. Para esse autor, competência é ação e resultado.

Abbad e Borges-Andrade (2004, p. 241), consideram que a competência quando usada em um sentido mais restrito aos ambientes de trabalho "envolve tanto o resultado como o desempenho esperado, assim como o conjunto de qualificações necessárias ao seu alcance”. 
A noção de competência reporta-se ao processo de aquisição de conhecimentos fundamentando suas análises na psicologia da aprendizagem, embora também utilize teorias de outras áreas do conhecimento. Nesse sentido, “aparece associada a verbos como: saber agir, mobilizar recursos, integrar saberes múltiplos e complexos, saber aprender, saber engajar-se, assumir responsabilidades, ter visão estratégica” (FLEURY; FLEURY, 2001, p. 187). Parece que essa noção, ao buscar justificação científica, tende a imbuir-se de uma pretensa neutralidade, já que centra seu foco no desenvolvimento de atitudes comportamentais e intelectuais e desvincula a formação profissional das relações contraditórias entre capital e trabalho.

Nesse sentido, para Fleury e Fleury (2001), sob a ótica da organização, as competências devem agregar valor tanto para a organização quanto para o indivíduo. Para a organização agrega o valor econômico; para o indivíduo, agrega valor social, conforme demonstrado na Figura 1.

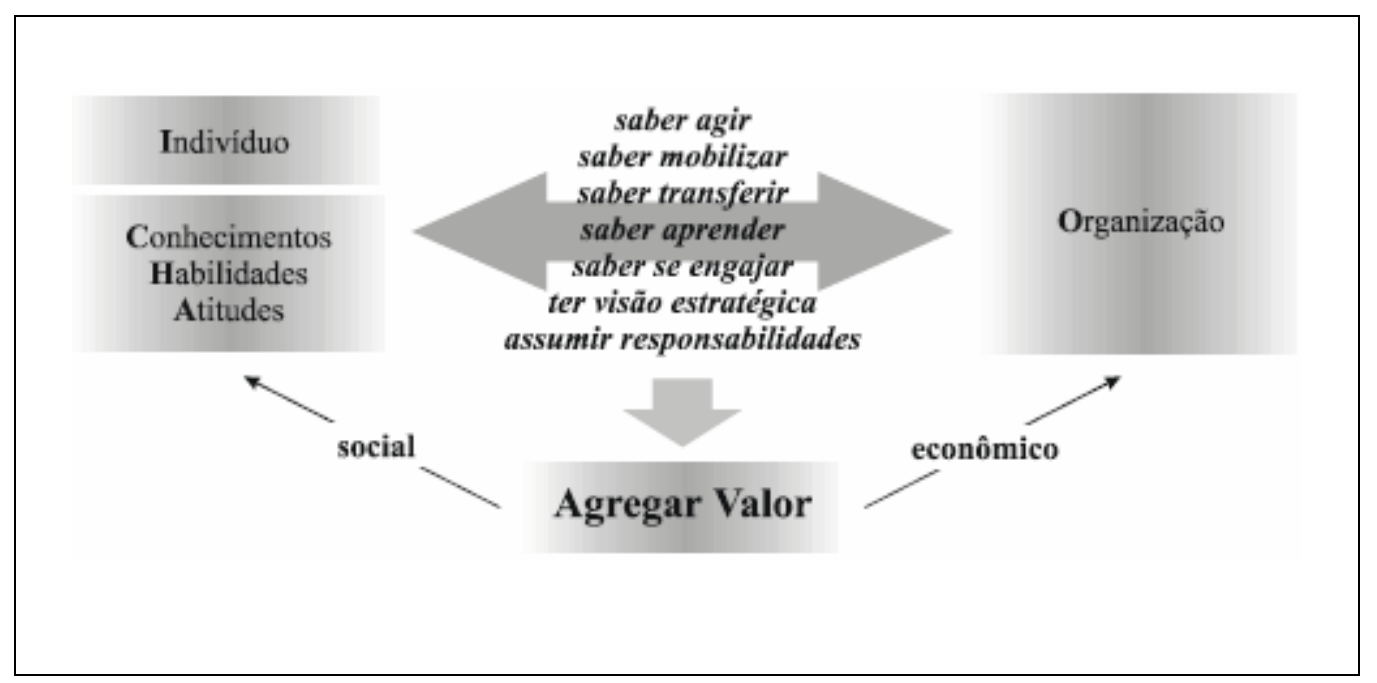

Figura 1 - Competência como fonte e valor para o indivíduo e para a organização Fonte: Fleury e Fleury (2001, p. 188)

Assim, para Fleury e Fleury (2001, p. 188), competência é “um saber agir responsável e reconhecido, que implica mobilizar, integrar, transferir conhecimentos, recursos e habilidades, que agreguem valor econômico à organização e valor social ao indivíduo”.

Observa-se que as características da competência, no que se referem ao desenvolvimento intelectual proveniente da aquisição de conhecimentos, qualidade de vida, relações sociais e grau de instrução, não se opõem à noção de qualificação profissional, mesmo porque, a qualificação não é um conceito estático e evolui no decorrer da história. 
Durand (1998; 2000 apud BRANDÃO; GUIMARÃES, 2001), adotando as idéias do pedagogo suíço Henri Pestalozzi, que idealizou a educação como o desenvolvimento natural, espontâneo e harmônico das capacidades humanas que se revelam na tríplice atividade da cabeça, das mãos e do coração (head, hand e heart), construiu um conceito de competência com base em três dimensões: i) conhecimentos; ii) habilidades; e iii) atitudes. A tríade sugerida por Pestalozzi (1974 apud BRANDÃO; GUIMARÃES, 2001), envolve não apenas questões técnicas, mas também a cognição e as atitudes relacionadas ao trabalho, conforme demonstrado na Figura 2.

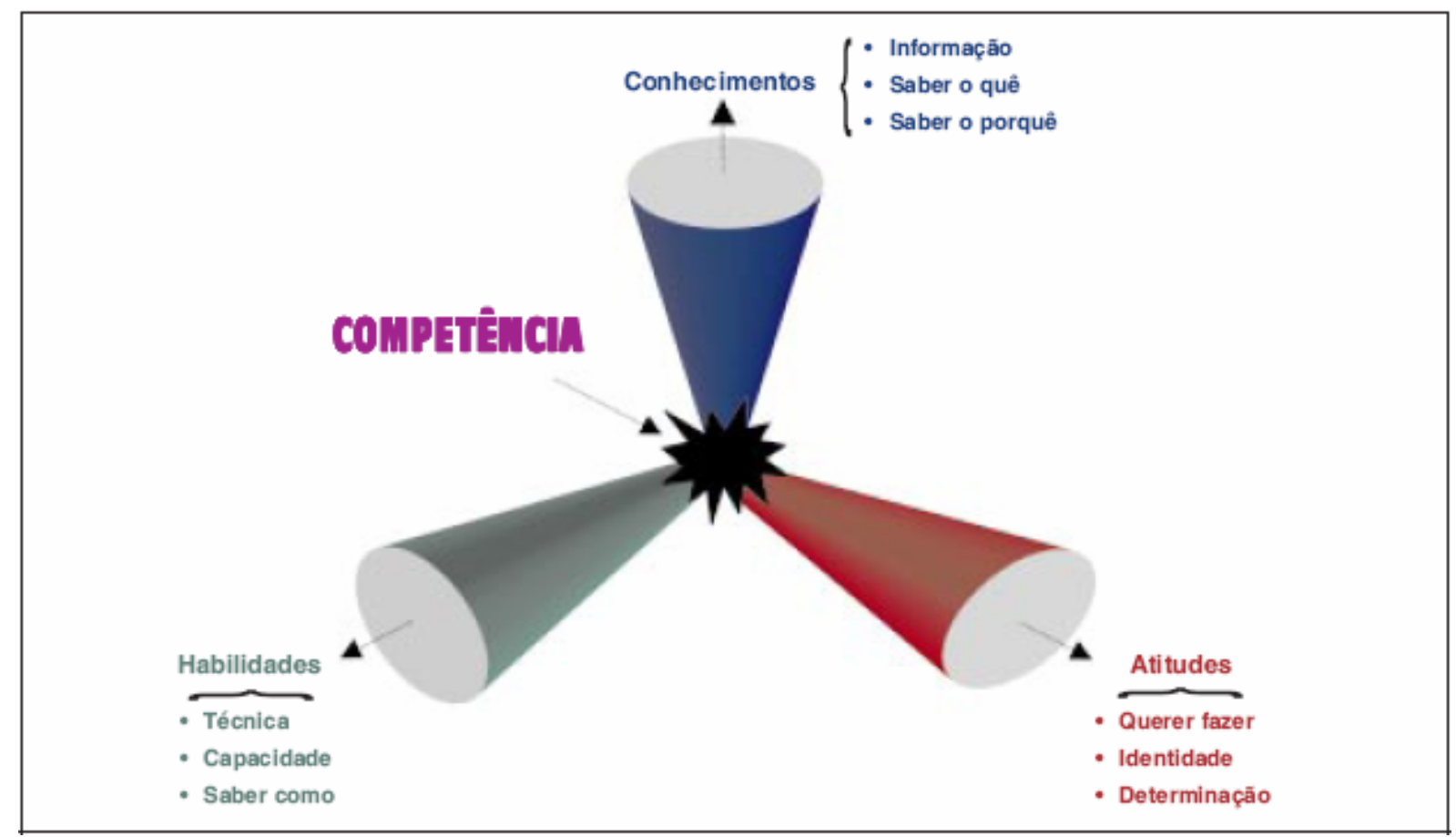

Figura 2 - As três dimensões da competência

Fonte: Adaptado de Durand (2000 apud BRANDÃO; GUIMARÃES, 2001, p. 10)

As três dimensões que apóiam o conceito de competência são definidas por Durand (1998 apud BRANDÃO; GUIMARÃES, 2002) da seguinte maneira:

a) Conhecimento - corresponde a uma série de informações assimiladas e estruturadas pelo indivíduo, que lhe permite “entender o mundo". Inclui a capacidade de receber informações e integrá-las dentro de um esquema preexistente, o pensamento e a visão estratégicos, o saber "o quê" e o "por quê";

b) Habilidade - refere-se à capacidade de aplicar e fazer uso produtivo do conhecimento, ou seja, agir de acordo com objetivos ou processos predefinidos, envolvendo técnica e aptidão; 
c) Atitude - diz respeito a aspectos afetivos e sociais relacionados ao trabalho. Inclui a identidade do indivíduo com os valores da organização e, por conseqüência, seu comprometimento e motivação para atender aos padrões de comportamento esperados para atingir resultados no trabalho com alto desempenho.

Bloom et al. (1973, 1979 apud BRANDÃO; GUIMARÃES; BORGES-ANDRADE, 2001), desenvolveram uma classificação de objetivos educacionais baseada em três domínios: i) cognitivo - objetivos vinculados à memória e ao desenvolvimento de capacidades intelectuais; ii) psicomotor - objetivos relacionados ao desenvolvimento de habilidades manipulativas ou motoras; e iii) afetivo - objetivos que descrevem mudanças de interesses, atitudes e valores.

As chaves de aprendizagem individual propostas por Pestalozzi (1974 apud BRANDÃO; GUIMARÃES, 2001), os domínios de objetivos educacionais sugeridos por Bloom et al. (1973, 1979 apud BRANDÃO; GUIMARÃES; BORGES-ANDRADE, 2001) e as dimensões da competência de Durand (1998, 2000 apud BRANDÃO; GUIMARÃES, 2001), são análogas; interdependentes e complementares, conforme apresentado na Figura 3.

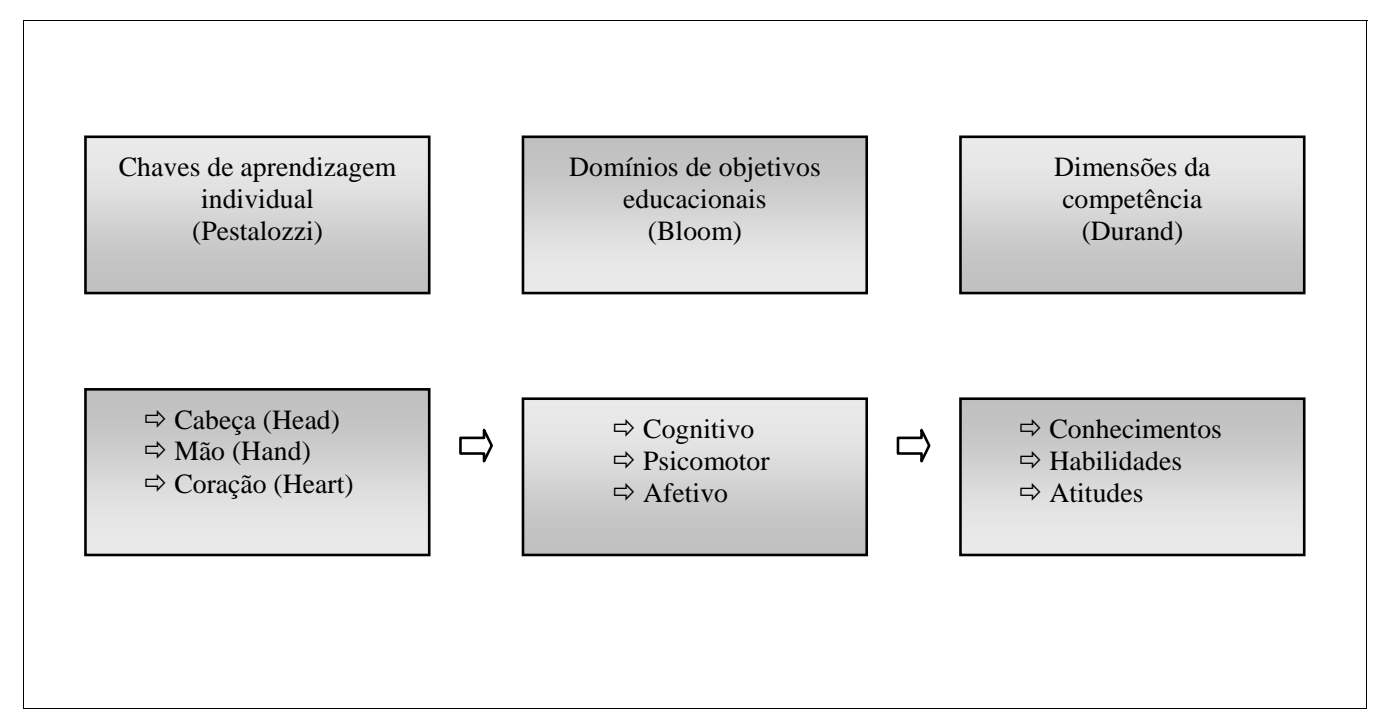

Figura 3 - Analogia entre as proposições de Pestalozzi, Bloom et al. e Durand Fonte: Brandão, Guimarães e Borges-Andrade (2001, p. 67)

A competência diz respeito ao conjunto de conhecimentos, habilidades e atitudes (CHA’s) necessário à consecução de determinado objetivo (BRANDÃO; GUIMARÃES, 2001).

Sob essa ótica, as dimensões de competência de Durand (1998; 2000 apud BRANDÃO; GUIMARÃES, 2001) 
[...] são interdependentes na medida em que, para a exposição de uma habilidade, se presume que o indivíduo conheça princípios e técnicas específicos. Da mesma forma, a adoção de um comportamento no trabalho exige da pessoa, não raras vezes, a detenção não apenas de conhecimentos, mas também de habilidades e atitudes apropriadas (BRANDÃO; GUIMARÃES, 2001, p. 10).

As características da abordagem individual do conceito de competência aplicam-se também à equipe de trabalho e à organização como um todo (BRANDÃO e GUIMARÃES, 2001).

Para Durand (1998 apud BRANDÃO; GUIMARÃES, 2002), as competências se desenvolvem por meio da aprendizagem individual e coletiva, envolvendo simultaneamente as três dimensões. Nesse sentido, para esse autor, competência é a assimilação de conhecimentos, integração de habilidades e adoção de atitudes relevantes a um contexto organizacional específico ou para a obtenção de alta performance no trabalho.

Guimarães et al. (2001 apud BRUNO-FARIA; BRANDÃO, 2003), construíram um modelo de gestão de desempenho com base nas competências que implica na gestão da organização em planejar, selecionar, desenvolver e remunerar profissionais, com ênfase nas competências essenciais das organizações e dos indivíduos. A essência desse modelo consiste em identificar as competências necessárias à concretização da visão de futuro das pessoas e da organização e, então, elaborar um mapeamento de competências internas. Essa visão mostra o rumo desejado - o futuro estratégico da empresa - e serve de orientação para políticas e práticas para reduzir ao mínimo o gap entre as competências existentes e aquelas necessárias ao cumprimento dos objetivos e metas organizacionais.

Brandão e Guimarães (2001), ao tratarem da gestão de competências e da gestão de desempenho, constataram que o conceito de competência é associado à ação, e concluíram que não é possível tratar da gestão de competências sem considerar a gestão de desempenho, uma vez que a competência representa o próprio desempenho e este representa uma manifestação da competência. Para esses autores, a gestão de competências e a gestão de desempenho, mais que tecnologias independentes e distintas, representam instrumentos que se complementam em um contexto mais amplo de gestão organizacional. Esse contexto integra em um único modelo de gestão as atividades de planejamento, acompanhamento e avaliação de desempenho, a partir de um mapeamento de competências desde o nível da organização até o individual, como sugerido por Guimarães et al. (2001 apud BRUNO-FARIA; BRANDÃO, 2003, p. 38), conforme retrata a Figura 4. 


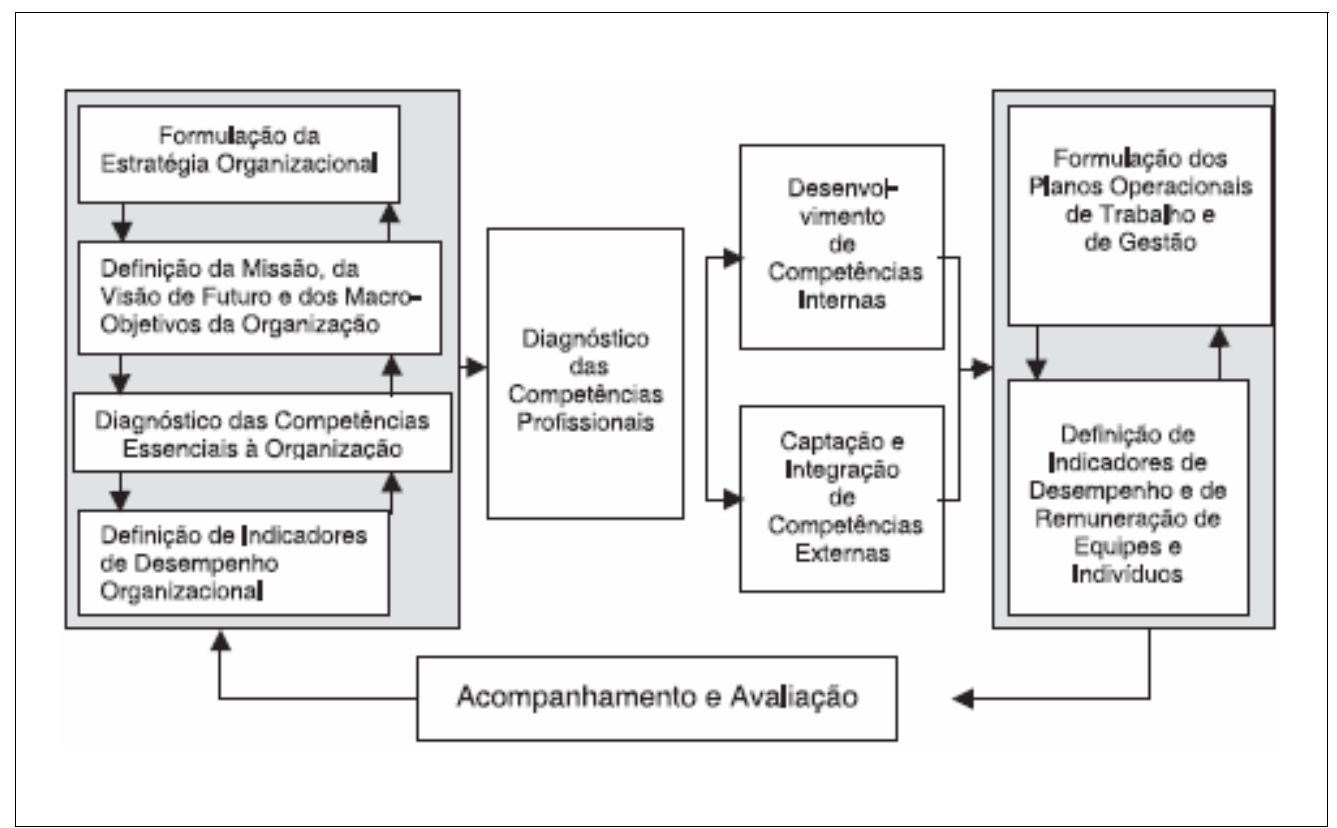

Figura 4 - Modelo de gestão de desempenho baseada nas competências

Fonte: Adaptado de Guimarães et al. (2001 apud BRUNO-FARIA; BRANDÃO, 2003, p. 38)

A descrição de uma competência, então, "representa um desempenho ou comportamento esperado, indicando o que o profissional deve ser capaz de fazer" (CARBONE et al., 2005, p. 56).

Assim, as competências, por serem dinâmicas, podem ganhar ou perder relevância ao longo do tempo e estão diretamente relacionadas ao contexto em que estão inseridos os profissionais. Nesse sentido, Jonnaert e Borght (2002, p. 47) afirmam que "uma competência é uma função da situação enfrentada e que um poderoso indicador de competência reside no êxito do enfrentamento de uma dada situação”.

\section{3 - Competência organizacional}

No nível organizacional, as competências são usualmente denominadas core competences, são as competências essenciais. As competências essenciais são o conjunto de habilidades e tecnologias - e não uma única habilidade ou tecnologia isolada - que habilitam uma companhia a proporcionar um benefício particular para os clientes, mais do que uma habilidade ou tecnologia (PRAHALAD, 1999; PRAHALAD; HAMEL, 2005). Esses autores se referem à competência essencial como a raiz da competitividade, em mercados inexistentes e futuros, e ainda tratando-a como um atributo que confere vantagem competitiva à organização e gera valor distintivo percebido pelos clientes. Ainda na visão desses autores, as organizações devem se desenhar em torno de suas competências essenciais. 
Para Guimarães e Medeiros (2003), as organizações podem ter um leque de capacidades e competências, mas poucas são as competências que podem ser consideradas como essenciais. Portanto, “embora muitas organizações tenham competências, nem todas têm competências essenciais. Se as competências não produzem bens ou serviços percebidos pelos clientes como sendo de valor superior, não podem ser consideradas essenciais” (GUIMARÃES; MEDEIROS, 2003, p. 259).

Porém, para Prahalad (1999) e Prahalad e Hamel (2005), além de ser um portfólio de atividades distintas, uma empresa é um portfólio de competências essenciais, que são uma combinação de várias tecnologias hard e soft; de aprendizado coletivo multinível e multifuncional; e de capacidade de compartilhar além das fronteiras empresariais e geográficas. Como exemplo de competência organizacional, esses autores citam a capacidade de miniaturização da Sony e o design de motores leves e eficientes da Honda.

A oportunidade da empresa em identificar as suas competências lhe oferece condições para realizar investimentos e alocar recursos em focos estratégicos. Outros autores preferem utilizar o termo “competência organizacional” (FLEURY; FLEURY, 2001; RUAS, 2000; RUAS 2001), por considerarem que o conceito “competência essencial” está mais apropriado a empresas que criam e lideram um espaço de competição, o que não parece adequado no cenário empresarial brasileiro.

No entendimento de Moura e Bitencourt (2006), as competências organizacionais provêm da especificidade de cada empresa para identificar seus recursos e transformá-los em vantagem competitiva. Os processos de conversão de recursos em competências organizacionais nem sempre são planejados e desenhados, mas ocorrem no cenário competitivo e provocam a dinâmica organizacional. Nesse sentido, a estratégia aparece alinhada às competências da empresa, enquanto o seu compartilhamento em competências coletivas ou individuais passa por níveis hierárquicos e equipes de trabalho. “A efetividade da organização resulta da capacidade de articular o seu direcionamento estratégico com as competências da empresa, dos grupos e das competências individuais” (MOURA; BITTENCOURT, 2006, p. 3).

\section{4 - Relação entre competência e desempenho competente}

É possível classificar as competências como individuais ou profissionais e organizacionais. Brandão e Guimarães (2001) consideram uma competência individual ou 
profissional aquela relacionada à pessoa ou a equipes de trabalho, enquanto que a competência organizacional são aquelas inerentes à organização como um todo ou uma de suas unidades de produção.

A corrente da gestão de competências argumenta que "a competência humana, aliada a outros recursos, dá origem e sustentação à competência organizacional” (BRANDÃO; GUIMARÃES, 2001, p. 13). Para os que defendem a corrente da gestão de desempenho, a performance do indivíduo no trabalho é resultante não apenas de suas competências individuais, mas também de atributos organizacionais, o que parece associar o desempenho ou as competências humanas com o desempenho ou as competências organizacionais. Essa associação conduz a gestão de desempenho e a de competências a um contexto de gestão estratégica de recursos humanos (BRANDÃO; GUIMARÃES, 2001).

Para Carbone et al. (2005),

[...] parece mais indicado descrever competências humanas sob a forma de referenciais de desempenho, ou seja, de comportamentos passíveis de observação no ambiente de trabalho, pois, o desempenho representa uma expressão, uma manifestação da competência (CARBONE et al., 2005, p. 56)

Considerando essas semelhanças conceituais entre competência e desempenho, “o resultado alcançado pelo indivíduo - o desempenho - representa, em última instância, a própria competência do indivíduo” (BRANDÃO; GUIMARÃES, 2001, p. 13).

Nesse sentido, Abbad, Freitas e Pilati (2005), consideram que

[...] um desempenho competente é aquele que se aproxima de padrões ou atende certos critérios de excelência com muita freqüência e por um período longo de tempo. Em um sentido ideal, uma ação de TD\&E deve ter efeito durável e também melhorar o nível de desempenho da pessoa treinada em atividades similares e em outras que requeiram o uso de novos CHA's. Uma ação de TD\&E cujos efeitos positivos são fugazes, como é o caso de alguns cursos de habilidades interpessoais, que geram satisfação e disposição para mudar atitudes por um ou dois dias após a conclusão, é geralmente considerado ineficaz (ABBAD; FREITAS; PILATI, 2005, p. 15).

A competência ou desempenho exemplar é função de múltiplos fatores. "São condições necessárias ao desempenho competente: i) os conhecimentos essenciais à aquisição de conhecimentos, habilidades e atitudes - CHA's (saber 'o que e como', saber 'fazer' e saber 'ser’); ii) a motivação ('querer’ fazer); iii) as condições ambientais adequadas ('poder' fazer) para adquirir, reter e aplicar novos CHA’s em diferentes situações e contextos” (ABBAD; BORGES-ANDRADE, 2004, p. 256). 
Corroborando com essa abordagem, Abbad, Freitas e Pilati (2005) também citam que são necessárias certas condições para que o indivíduo obtenha um desempenho eficaz. Precisa saber fazer e querer fazer a tarefa de acordo com certo padrão. Faz-se necessário ainda um suporte organizacional para execução eficaz da tarefa. As idéias desses autores são demonstradas na Figura 5.

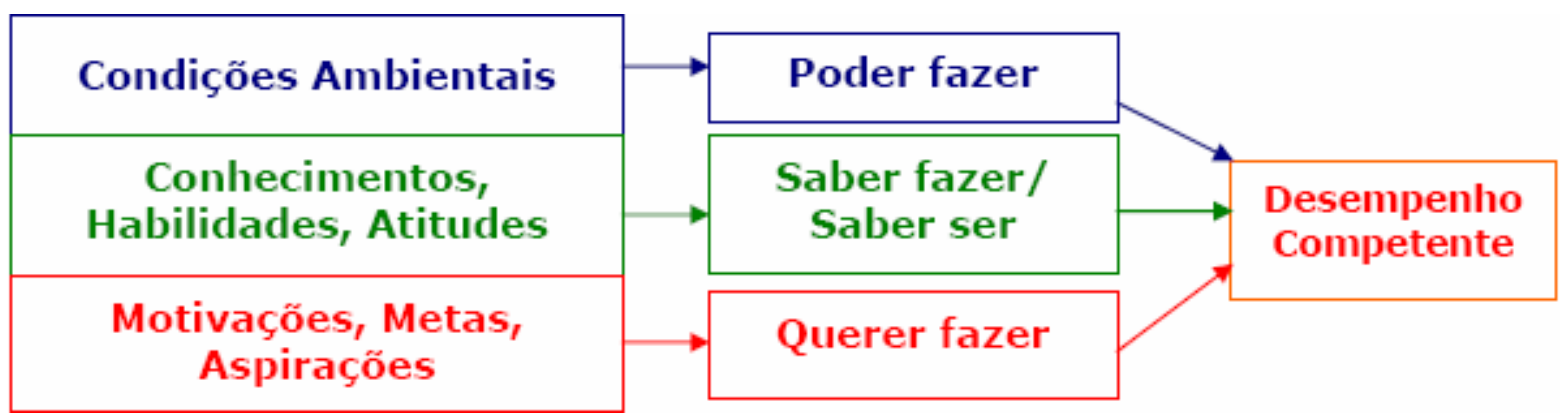

Figura 5 - Condições necessárias ao desempenho competente

Fonte: Abbad e Borges-Andrade (2004 apud ABBAD; FREITAS; PILATI, 2005, p. 15)

As organizações modernas têm buscado subsídios nos modelos de gestão de competências para planejar, selecionar e desenvolver as competências necessárias às suas respectivas áreas de atuação no mercado.

O modelo sugerido por Ienaga (1998 apud BRANDÃO; GUIMARÃES, 2001), realiza o diagnóstico ou mapeamento das competências (organizacionais e individuais), identificando assim o gap (lacuna) de competências, ou seja, a discrepância existente entre as competências necessárias ao alcance do desempenho esperado e as competências já disponíveis na organização, conforme demonstrado na Figura 6.

A ênfase desse modelo consiste

[...] em estabelecer os objetivos e as metas a serem alcançados segundo a intenção estratégica da organização e, depois, identificar a lacuna entre as competências necessárias à consecução desses objetivos e as competências internas disponíveis na empresa. Os passos seguintes compreendem o planejamento, a seleção, o desenvolvimento e a avaliação de competências, buscando minimizar a referida lacuna, o que pressupõe a utilização de diversos subsistemas de recursos humanos, entre os quais, recrutamento e seleção, treinamento e gestão de desempenho (BRANDÃO; GUIMARÃES, 2001, p. 11). 


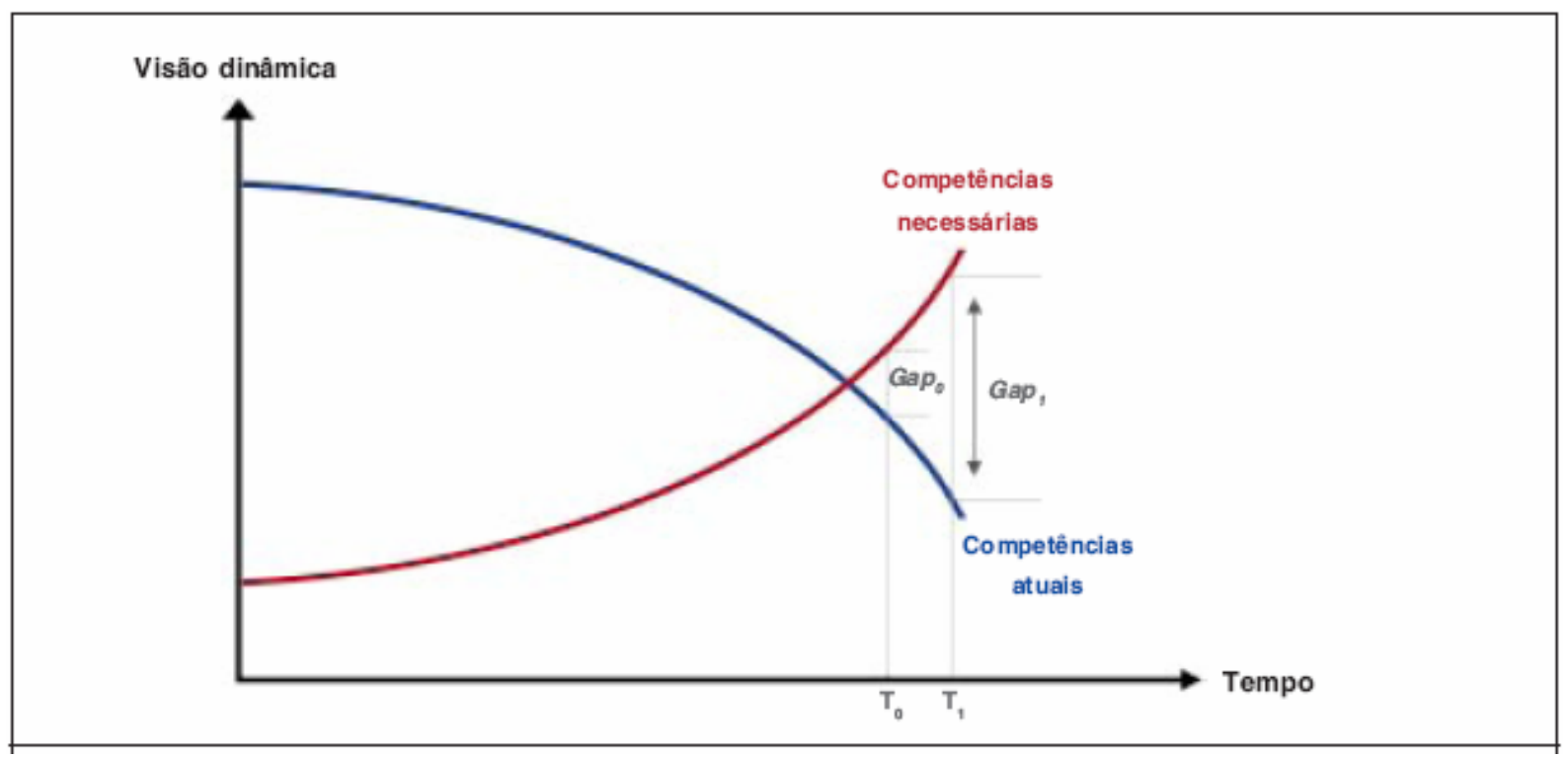

Figura 6 - Identificação do gap (ou lacuna) de competências

Fonte: Adaptado de Ienaga (1998 apud BRANDÃO; GUIMARÃES, 2001, p. 11)

Ressalte-se que, se não houver por parte da organização ações de captação e/ou desenvolvimento de competências, esse gap tende a aumentar, conforme demonstra a figura 4 (CARBONE et al., 2005; BRUNO-FARIA; BRANDÃO, 2003). Nesse sentido, captação corresponde à seleção de competências externas e sua incorporação ao ambiente organizacional, que pode ocorrer no nível individual, por meio de ações de recrutamento e seleção, e no nível organizacional, por meio de joint-ventures ou alianças estratégicas. $\mathrm{O}$ desenvolvimento diz respeito ao "aprimoramento das competências internas disponíveis na organização, podendo ocorrer no nível individual por intermédio de treinamento e, no nível organizacional, por meio de investimentos em pesquisas” (BRUNO-FARIA; BRANDÃO, 2003, p. 39-40).

O complexo ambiente no qual as organizações estão inseridas, onde as mudanças tecnológicas ocorrem de forma vertiginosa e turbulenta, exige cada vez mais novas competências, o que tende a elevar a curva das competências necessárias para a obtenção dos objetivos e metas organizacionais. A curva que representa as competências internas pode tender a decrescer caso essas competências se tornem obsoletas. Nesse sentido, é de fundamental importância que o mapeamento ou diagnóstico das competências seja realizado periodicamente, bem como o planejamento de captação e/ou do desenvolvimento de competências, para se alinhar aos objetivos estratégicos da organização (CARBONE et al., 2005). 


\section{5 - Competências gerenciais}

O cenário competitivo por que passam as organizações e a necessidade de desenvolver nas pessoas as competências gerenciais necessárias para acompanhar e gerar as mudanças desejadas no seu ambiente, faz com que muitas empresas comecem a repensar o atual modelo de gestão das competências, onde "as tradicionais práticas de treinamento e desenvolvimento parecem não responder às novas demandas do mercado” (BITENCOURT, 2003, p. 135).

Seguindo essa tendência, muitas empresas, alertas à nova configuração dos mercados, perceberam que, aliado à atualização do parque tecnológico, o investimento na geração de novos conhecimentos e o desenvolvimento de novas competências gerenciais em seus colaboradores podem projetar a organização a conseguir vantagens competitivas únicas e ganhos até então não mensuráveis (DAVEL; MELO, 2005). Nesse sentido, os autores afirmam que:

Tal estratégia, plenamente alicerçada nos ativos humanos, revela que a capacidade de inovação está diretamente ligada às condições propiciadas pelas empresas ao processo de aprendizagem, como canais de comunicação abertos, incentivo ao diálogo e ao trabalho em equipe e decisões compartilhadas, de forma a propiciar um campo de interação e fazer aflorar todo o potencial criativo dos indivíduos. Contudo, trata-se de processos e não de ações em curto prazo (DAVEL; MELO, 2005, p. 274).

Segundo Prahallad e Hamel (2005), as novas fontes de vantagem competitiva têm exigido das organizações mudanças cada vez mais rápidas, profundas e abrangentes. Em conseqüência, as organizações buscam "envolver e desenvolver as pessoas para que as mudanças requeridas sejam efetivas” (BITENCOURT, 2003, p. 135).

Nesse contexto, o papel e as funções dos gerentes são fundamentais no cumprimento dos objetivos organizacionais, pois eles têm a função de atingir os resultados por meio das pessoas. Segundo Davel e Melo (2005, p. 37), “os gerentes favorecem a execução de um trabalho em quantidade e qualidade suficientes para a manutenção da cooperação e a garantia da reprodução das relações sociais”.

Em várias pesquisas realizadas sobre as atividades dos gerentes, entre os anos de 1960 e 1970, Mintzberg (1973 apud DAVEL; MELO, 2005), a partir de suas observações, confirmou as conclusões de autores pioneiros que estudaram os trabalhos diários dos gerentes. Assim, o autor constatou que: i) o trabalho dos gerentes é realizado num ritmo implacável; ii) sua rotina do trabalho é repleta de ações breves, variadas e fragmentadas; iii) servem de ponte 
entre sua organização e as redes externas a elas; iv) decidem sobre a utilização de seu próprio tempo.

As propostas resultantes dessas observações foram agrupadas em três tipos de papéis e funções dos gerentes, quais sejam: i) papéis interpessoais; ii) papéis informacionais; e iii) papéis decisórios. Esses papéis dificilmente podem ser vistos de forma fragmentada (MINTZBERG, 1973 apud DAVEL; MELO, 2005, p. 73).

O Quadro 1 demonstra os três papéis e funções dos gerentes com suas respectivas descrições.

\begin{tabular}{|c|c|}
\hline \multicolumn{2}{|r|}{ Papéis interpessoais } \\
\hline Símbolo & $\begin{array}{l}\text { Representa a organização em todo tipo de cerimônia e contribui para a imagem } \\
\text { da organização. }\end{array}$ \\
\hline Líder & * Serve de exemplo, motiva e mobiliza as pessoas na organização. \\
\hline Agente de Ligação & $\begin{array}{l}\text { * Cria e mantém redes de informantes, participa de diferentes redes de } \\
\text { informação, tanto dentro quanto fora da organização. }\end{array}$ \\
\hline \multicolumn{2}{|r|}{ Papéis informacionais } \\
\hline Observador & $\begin{array}{l}\text { * Busca e recebe informações relativas à gestão da empresa, ao conhecimento do } \\
\text { seu ambiente ou ao impacto de suas atividades. }\end{array}$ \\
\hline Difusor & $\begin{array}{l}\text { Difunde os elementos pertinentes das informações recebidas e assegura-se de } \\
\text { que as informações cheguem bem aos destinatários desejados. }\end{array}$ \\
\hline Porta-voz & * Propaga as informações de dentro para fora da organização \\
\hline \multicolumn{2}{|r|}{ Papéis decisórios } \\
\hline Empreendedor & $\begin{array}{l}\text { Está sempre à espreita de oportunidades de negócios na empresa e em torno } \\
\text { dela. }\end{array}$ \\
\hline Regulador & $\begin{array}{l}\text { * Enfrenta toda situação nova e organiza a reação e a adaptação da organização às } \\
\text { situações difíceis. }\end{array}$ \\
\hline Distribuidor de recursos & $\begin{array}{l}\text { Distribui recursos, a fim de que cada um disponha dos meios necessários para } \\
\text { cumprir bem suas tarefas na organização. }\end{array}$ \\
\hline Negociador & $\begin{array}{l}\text { Participa de algumas discussões, como representante de sua organização, com } \\
\text { interlocutores externos. }\end{array}$ \\
\hline
\end{tabular}

Quadro 1 - Papéis e funções dos gerentes

Fonte: Adaptado de Mintzberg (1973 apud DAVEL; MELO, 2005, p. 73)

Em vários estudos, pesquisas e contribuições realizados na busca de um modelo de gestão que atenda às necessidades da empresa moderna, Dutra (2004), elencou as competências específicas fundamentais para a sobrevivência da organização e centrais para o cumprimento de sua estratégia por meio daqueles que são imprescindíveis no âmbito organizacional - o gerente. Para o autor, as empresas perceberam que a moeda de troca mais valorizada atualmente é a do desenvolvimento contínuo de seus talentos. O Quadro 2 
relaciona essas competências e descreve cada uma delas de acordo com o resultado da pesquisa realizada pelo autor.

\begin{tabular}{|c|c|}
\hline Competências Gerenciais & Aspectos \\
\hline Planejamento e Organização & $\begin{array}{l}\text { Q Relacionam-se a organização, sistematização, antecipação de tendências que } \\
\text { facilitem o processo de decisão de líderes e gerentes. Objetivam garantir } \\
\text { qualidade, facilidade de acesso, velocidade, disciplina na execução das ações } \\
\text { e obtenção dos resultados. }\end{array}$ \\
\hline Comunicação & $\begin{array}{l}\text { Transmitir informações e conhecimentos de forma a ser compreendido por } \\
\text { qualquer interlocutor e em qualquer ambiente; } \\
\text { a Saber ouvir e dar feedback; } \\
\text { a Utilizar eficientemente os recursos de comunicação disponíveis na empresa. }\end{array}$ \\
\hline Negociação & $\begin{array}{l}\text { Inclui a busca pelo equilíbrio dos resultados de uma negociação, visando a } \\
\text { benefícios para os envolvidos, buscando gerar credibilidade e criar } \\
\text { relacionamentos necessários para a obtenção dos resultados desejados; } \\
\text { ه Abrange a construção de uma argumentação coerente e abertura para rever } \\
\text { posições e entender pontos de vista distintos dos seus. }\end{array}$ \\
\hline Gestão do conhecimento & $\begin{array}{l}\text { Q Reconhece em seu campo de atuação [a necessidade de] agregar valor ao } \\
\text { processo de gestão do conhecimento, atuando sistematicamente na captura, } \\
\text { criação, disponibilização, disseminação e aplicação de conhecimento no } \\
\text { ambiente interno, bem como incentivando parceiros externos a gerar soluções } \\
\text { e conhecimentos que se traduzam em resultados práticos para a organização; }\end{array}$ \\
\hline Visão sistêmica & $\begin{array}{l}\text { Envolve o entendimento de todo o negócio, da relação entre os processos } \\
\text { organizacionais e da clareza sobre sua agregação de valor ao negócio; } \\
\text { Busca resultados, conciliando a visão de negócios nas dimensões técnica, } \\
\text { econômica e social, integrando pessoas e recursos existentes nos ambientes } \\
\text { interno e externo. }\end{array}$ \\
\hline Capacidade analítica & $\begin{array}{l}\text { Q Relaciona-se à responsabilidade pela captação e organização sistemática de } \\
\text { informações relativas a assuntos ou problemas, dentro de seu escopo de } \\
\text { atuação, através de análise, comparação e identificação de relações de causa e } \\
\text { efeito e alternativas de soluções de problemas. }\end{array}$ \\
\hline $\begin{array}{l}\text { Relacionamento } \\
\text { interpessoal/Articulação }\end{array}$ & $\begin{array}{l}\text { Envolve o desenvolvimento de relações estratégicas e responsabilidade por } \\
\text { utilizar redes de relacionamento (networks) na busca de maximização dos } \\
\text { resultados, agregação de valor e identificação de oportunidades para a } \\
\text { organização e seus parceiros. }\end{array}$ \\
\hline Multifuncionalidade & $\begin{array}{l}\text { ב Envolve a mobilização de uma diversidade de conhecimentos e informações, } \\
\text { adaptando-se a vários papéis e ajustando-se para responder adequadamente a } \\
\text { novas estruturas organizacionais, processos, demandas ou outras } \\
\text { modificações ambientais. É flexível em lidar com mudanças, fazendo-o de } \\
\text { forma consistente ao investir no autodesenvolvimento. }\end{array}$ \\
\hline Gerenciamento de projetos & $\begin{array}{l}\text { Visa elaborar, estruturar, avaliar e controlar projetos, em termos de } \\
\text { gerenciamento de tempos, recursos, resultados e definição de prioridades, de } \\
\text { maneira integrada aos processos organizacionais em vigor. }\end{array}$ \\
\hline Orientação para resultados & $\begin{array}{l}\text { Atuação independente, ou envolvendo membros da equipe, voltada para os } \\
\text { resultados e rentabilidade da empresa; } \\
\text { atua com determinação e foco, obtendo e/ou superando de forma consistente } \\
\text { e com qualidade os desafios assumidos. }\end{array}$ \\
\hline
\end{tabular}




\begin{tabular}{|c|c|}
\hline Competências Gerenciais & Aspectos \\
\hline Liderança & $\begin{array}{l}\text { Delega a seus liderados, com precisão e limites adequados, missões e } \\
\text { desafios, promovendo o acompanhamento e o apoio necessários para que eles } \\
\text { alcancem os objetivos. }\end{array}$ \\
\hline Visão estratégica & $\begin{array}{l}\text { Q Visão global e de futuro, que permite identificar riscos e oportunidades } \\
\text { capazes de causar impacto na empresa, no âmbito de sua área de atuação. }\end{array}$ \\
\hline Inovação & $\begin{array}{l}\text { Relaciona-se à gestão de processos de melhoria e inovação, desde o } \\
\text { planejamento até sua implementação, envolvendo identificação sistemática } \\
\text { de pontos para superação dos resultados alcançados, transformação de } \\
\text { problemas em oportunidades, criação de múltiplas alternativas originais e } \\
\text { seleção das mais eficazes, bem como a criação de indicadores específicos que } \\
\text { permitam aproximar ao máximo o acompanhamento das melhorias } \\
\text { implementadas. }\end{array}$ \\
\hline Agente de mudança & $\begin{array}{l}\text { 口 Influencia e lidera processo de mudança e transformação organizacional, } \\
\text { atuando de forma decisiva para o sucesso de sua implementação. }\end{array}$ \\
\hline
\end{tabular}

Quadro 2 - Competências gerenciais

Fonte: Adaptado de Dutra (2004)

Para Davel e Melo (2005, p. 326), “devido ao fato de o trabalho gerencial envolver um processo dinâmico e ser permeável às mudanças organizacionais, a identidade de 'ser gerente' é vulnerável a mudanças constantes”.

Nesse sentido, o trabalho dos gerentes passa pelo exercício do poder e pela mediação de interesses, pois muitos passam por situações constrangedoras quanto às funções e aos papéis desempenhados. Assim, “por mais ambivalentes, contraditórios e instáveis que sejam, os conteúdos do trabalho gerencial podem ser contemplados com base em cinco processos: i) atuação; ii) interação; iii) simbolização; iv) dominação; e v) assimilação” (DAVEL; MELO, 2005, p. 325).

São processos difíceis de serem ordenados em seqüência, haja vista que um não é obrigatoriamente conseqüência do outro, podendo até se sobrepor. O Quadro 3 apresenta os processos e principais características do trabalho gerencial, a partir das contribuições e dos estudos realizados por Davel e Melo (2005).

\begin{tabular}{|c|c|}
\hline Processos & Características \\
\hline Atuação & $\begin{array}{l}\text { 口 Jornadas de trabalho compostas de ações breves, variadas, descontínuas e fragmentadas. } \\
\text { a Preferência por comunicações verbais (discussões informais, reuniões, conversas telefônicas, } \\
\text { atividades sociais) e pela atuação direta, em vez de trabalho de reflexão e de meios. } \\
\text { a Busca de respaldo institucional em práticas de sucesso. }\end{array}$ \\
\hline Interação & $\begin{array}{l}\text { C Criação e manutenção de redes de relações intra e extra-organizações. } \\
\text { a Construção de alianças com a equipe de trabalho e os pares, buscando resguardar seu espaço } \\
\text { na organização. } \\
\text { a Relação multivariada com a equipe de trabalho. } \\
\text { a Dificuldade de conciliar vida profissional com vida familiar. }\end{array}$ \\
\hline
\end{tabular}




\begin{tabular}{|c|c|}
\hline Processos & Características \\
\hline Simbolização & $\begin{array}{l}\text { Delimitação, tradução, negociação e transmissão da realidade organizacional por intermédio } \\
\text { da linguagem, de símbolos, de imagens etc., disponíveis a partir da história sociocultural da } \\
\text { organização e do local em que se insere. } \\
\text { O contexto sociocultural do Brasil fornece um repertório de recursos (conhecimento pessoal, } \\
\text { proximidade pessoal, criatividade, improvisação, jogo de cintura, etc.) e regras (pessoalidade, } \\
\text { cordialidade, autoritarismo, formalismo, imediatismo, etc.) aos gerentes. } \\
\square \text { O contexto político (relações de poder) sustenta um campo mal definido de espaço de ação, } \\
\text { favorecendo o desenvolvimento de ritos e símbolos que mascaram essa realidade. } \\
\square \text { O contexto pós-moderno fornece imagens e símbolos do gerente como personagem flexível } \\
\text { (por exemplo, homem-camaleão), que passa por processos identificadores cada vez mais } \\
\text { efêmeros para se adaptar velozmente (como o gerente minuto) aos modismos gerenciais. }\end{array}$ \\
\hline Dominação & $\begin{array}{l}\square \text { Validação dos interesses pessoais na arena dos jogos de poder organizacionais. } \\
\text { Capacidade de desenvolver processos de mediação e de regulação de interesses divergentes. } \\
\square \text { Defesa de um regime econômico que é dissimulado por meio de instrumentos ideológicos, } \\
\text { embora o trabalho gerencial não se reduza à função de capital. }\end{array}$ \\
\hline Assimilação & $\begin{array}{l}\square \text { Mobilização de outros valores, agendas e preocupações para propagar, resistir ou circundar } \\
\text { pressões projetadas para que suas ações sejam mais previsíveis e lucrativas. } \\
\square \text { Sentimento de traição e de mal-estar. } \\
\square \text { Aprendizagem e criação de novos conhecimentos, por intermédio, por exemplo, de processos } \\
\text { de resolução de problemas. } \\
\square \text { Experimentação e repasse do estresse oriundo do tipo de tarefa, da tensão entre a carreira e a } \\
\text { vida privada, das relações com os outros, do modo de gestão e do contexto sociocultural. }\end{array}$ \\
\hline
\end{tabular}

Quadro 3 - Processos e principais características do trabalho gerencial

Fonte: Davel e Melo (2005, p. 325-326)

Ao tratar da reforma gerencial da administração pública no Brasil, Bresser Pereira (1999) trata o ocupante de função de chefia como protótipo do administrador burocrático que precisa se transformar em gerente, ressaltando que o primeiro é uma categoria homogênea a ser superada.

Nesse sentido, Davel e Melo (2005) comentam que

[...] ao classificar o "burocrata" aquele que exerce um cargo de chefia, a abordagem da administração pública gerencial engessa e reduz a ação e o trabalho gerencial a uma única forma, oriunda daquela ligada ao tipo ideal weberiano. Daí o administrador burocrata ser considerado um mero cumpridor de regras impessoais, reprodutor ou implementador de decisões tomadas em outras instâncias, dogmático e orientado por interesses próprios, enquanto o gerente seria o tomador de decisões, o empreendedor, orientado por resultados e pelo mercado, pragmático e estratégico, buscando sempre os melhores interesses de eficiência e eficácia da organização (DAVEL; MELO, 2005, p. 144).

Nos estudos em busca da eficiência da máquina do Estado, Bresser Pereira (1999, p. 24) trata a gestão pública de forma mais ampla e comenta que “a administração pública gerencial está baseada em uma concepção de Estado e de sociedade democrática e plural, enquanto a administração pública burocrática tem um vezo centralizador e autoritário”. 
Com base nos pressupostos da teoria da estruturação, Davel e Melo (2005) mostram que a ação gerencial na administração pública brasileira está realmente apoiada em características estruturais da nossa sociedade.

Nesse sentido, a preocupação é de definir políticas e ações administrativas suficientemente claras e transparentes, que busquem garantir que o interesse coletivo na produção de bens públicos pelo Estado seja minimamente atendido (BRESSER PEREIRA, 1999).

Segundo Kilimnik, Sant'anna e Luz (2005), as políticas de gerenciamento das organizações podem tornar fáceis ou difíceis o desenvolvimento de competências. Para esses autores, se torna extremamente necessária a adaptação das empresas ao novo mundo dos negócios, visando a uma modernidade que contribua para a efetiva utilização das competências de seus profissionais para o alcance dos objetivos organizacionais.

Considerando esse cenário, Kilimnik, Sant’anna e Luz (2005), em estudo de campo realizado com profissionais de organizações mineiras e com base em revisão dos principais estudos sobre competência, elaboraram um painel de competências profissionais requeridas, considerando a modernidade organizacional. O Quadro 4 apresenta as quinze competências profissionais requeridas.

\begin{tabular}{|c|c|}
\hline \multirow{15}{*}{$\begin{array}{l}\text { Competências profissionais } \\
\text { requeridas }\end{array}$} & Capacidade de aprender rapidamente novos conceitos e tecnologias; \\
\hline & 口 Capacidade de trabalhar em equipe; \\
\hline & C Criatividade; \\
\hline & 口 Visão de mundo ampla e global; \\
\hline & a Capacidade de comprometer-se com os objetivos da organização; \\
\hline & 口 Capacidade de comunicação; \\
\hline & Capacidade de lidar com incertezas e ambigüidades; \\
\hline & $\begin{array}{l}\text { Domínio de novos conhecimentos técnicos associados ao exercício do } \\
\text { cargo ou função ocupada; }\end{array}$ \\
\hline & 口 Capacidade de inovação; \\
\hline & Capacidade de relacionamento interpessoal; \\
\hline & 口 Iniciativa de ação e decisão; \\
\hline & autocontrole emocional; \\
\hline & 口 Capacidade empreendedora; \\
\hline & $\square$ Capacidade de gerar resultados efetivos; \\
\hline & 口 Capacidade de lidar com situações novas e inusitadas. \\
\hline
\end{tabular}


Essas competências, segundo Kilimnik, Sant'anna e Luz (2005), pretendem demonstrar e valorizar o conjunto de saberes, habilidades e atitudes, inseridos na vida profissional do indivíduo, uma vez que o mercado exige cada vez mais um elevado grau do conjunto de competências profissionais.

A prática gerencial, portanto, envolve um processo dinâmico e está sujeita às mudanças organizacionais, pois é influenciada pelas políticas organizacionais assim como é capaz de influenciá-las (MARRA; MELO, 2005).

Para controlar a ansiedade por um desempenho de excelência e desenvolver a capacidade de lidar com as pressões do dia-a-dia, os gerentes precisam aprender a inovar constantemente e desenvolver continuamente os conhecimentos, as habilidades e as atitudes, inerentes a um ser humano competente. Devem, portanto, "ser atores sociais, políticos, subjetivos e econômicos competentes” (DAVEL; MELO, 2005, p. 332). 


\section{3 - Metodologia}

Descrevem-se nesta etapa a metodologia e as técnicas de pesquisa adotadas no mapeamento das competências.

Constata-se na literatura que a definição metodológica para uma pesquisa empírica tem sido de fundamental importância para as pretensões do pesquisador, que deve informar o que pretende investigar e o porquê de tal pesquisa. Também tem como objetivo apresentar conceitos e exemplos sobre população, amostra e seleção dos sujeitos, objetos da pesquisa, dentre outros aspectos relacionados ao desenho da pesquisa (VERGARA, 2000).

A seguir são descritos: o tipo de pesquisa, a amostra a ser pesquisada, o instrumento a ser aplicado, os procedimentos a serem adotados e a forma de análise dos dados coletados.

\section{1 - Tipo de pesquisa}

Segundo Vergara (2000), existem várias taxonomias de tipos de pesquisa, de acordo com os critérios utilizados pelos autores que tratam do assunto. No estudo em questão, serão utilizados os critérios básicos propostos por Vergara (2000), que classifica os tipos de pesquisa quanto aos fins a que se destina e quanto aos meios de investigação.

Quanto aos fins a que se destina, a pesquisa realizada, conforme Vergara (2000), foi do tipo descritiva e aplicada. Descritiva porque visou caracterizar a população a ser estudada, especialmente quanto às percepções, expectativas e sugestões dos gerentes da área-meio de uma instituição federal de ensino superior. Aplicada porque foi motivada pela necessidade de resolver problemas reais, portanto, com finalidade prática (VERGARA, 2000).

Quanto aos meios, a pesquisa foi bibliográfica, documental e de campo. Bibliográfica porque para a fundamentação teórico-metodológica do trabalho foram realizadas pesquisas sobre o assunto em material científico publicado em livros, revistas, meios eletrônicos. A investigação foi também, documental porque se valeu de documentos internos da instituição que dizem respeito ao objeto de estudo, como, por exemplo: regimento interno, estatuto, plano de desenvolvimento institucional, circulares, ofícios, memorandos, balancetes. A pesquisa foi de campo, porque coletou dados primários na instituição em estudo, com a realização de entrevistas e uso de um formulário. 


\section{2 - População e Amostra}

Segundo Vergara (2000), nesta etapa pretende-se

[...] definir toda a população e a população amostral. Entende-se aqui por população não o número de habitantes de um local, como é largamente conhecido o termo, mas um conjunto de elementos (empresas, produtos, pessoas, por exemplo) que possuem as características que serão objeto de estudo. População amostral ou amostra é uma parte do universo (população) escolhida segundo algum critério de representatividade (VERGARA, 2000, p. 83).

Vergara (2000) define dois tipos de amostra: probabilística, baseada em procedimentos estatísticos, e não probabilística. A amostra probabilística subdivide-se em aleatória simples, a estratificada e a por conglomerado. Da amostra não probabilística, destacam-se as selecionadas por acessibilidade e por tipicidade.

Optou-se nesta pesquisa por utilizar a amostra não probabilística por acessibilidade e por tipicidade. Por acessibilidade porque "longe de qualquer procedimento estatístico, seleciona elementos pela facilidade de acesso a eles" e por tipicidade porque é "constituída pela seleção de elementos que o pesquisador considera representativos da população-alvo, o que requer profundo conhecimento dessa população” (VERGARA, 2000, p. 84).

O universo da pesquisa, portanto, foi o corpo gerencial da atividade-meio de uma Instituição Federal de Ensino Superior incluindo oito níveis hierárquicos de gerências. A amostra foi constituída por dezoito gerentes, o que correspondeu a 33\% do total de gerentes. A não participação de $67 \%$ dos gerentes deveu-se à inexistência de um instrumento validado para a pesquisa aliada ao pouco tempo disponível para a construção de um instrumento. A amostra foi composta da seguinte forma:

a) Identificação de oito gerentes, correspondendo aos oito níveis hierárquicos, que foram entrevistados individualmente, no local de trabalho, selecionados entre aqueles que possuíam maior conhecimento da estratégia, da missão, dos valores, dos processos e da cultura da organização, junto aos quais se realizou um primeiro levantamento das competências que consideravam necessárias ao desempenho de sue trabalho;

b) Identificação de dezoito gerentes dos oito níveis hierárquicos, entrevistados individualmente, no local de trabalho, relacionados às áreas de pesquisa como: planejamento estratégico, planejamento técnico, administração superior, 
contabilidade e finanças, administração de recursos humanos, desenvolvimento de recursos humanos, recursos materiais e patrimônio;

\section{3 - Instrumento}

Segundo Borges-Andrade e Lima (1983), para construção de um instrumento de pesquisa devem ser considerados os incidentes críticos, ou seja, a descrição de ocorrências, fatos e eventos relevantes relacionados a uma atividade e que vão indicar os conhecimentos, habilidades e atitudes (CHA’s) necessários a uma determinada atividade.

O instrumento de pesquisa utilizado foi construído com base nas primeiras oito entrevistas realizadas, na literatura da área e na consulta documental da instituição em estudo. A literatura e os documentos foram analisados e foram identificadas as competências necessárias à atuação de um gerente na administração pública.

Assim, com base nos dados coletados, foi elaborado um painel de competências gerenciais necessárias ao cumprimento dos objetivos estratégicos estabelecidos no Plano de Desenvolvimento Institucional (PDI), o qual foi utilizado para compor a terceira questão do roteiro de entrevista.

Segundo Lüdke (1986), ao lado da observação, a entrevista é um dos mais básicos instrumentos de coleta de dados e também "uma das principais técnicas de trabalho em quase todos os tipos de pesquisa utilizados nas ciências sociais” (LÜDKE, 1986, p. 33).

As entrevistas podem ser classificadas em: i) não-estruturada ou não padronizada quando há liberdade de percurso na condução das perguntas; ii) estruturada ou padronizada quando o entrevistador tem que seguir rigorosamente um roteiro de perguntas feitas a todos os entrevistados de maneira idêntica e na mesma ordem; e iii) semi-estruturada - quando a entrevista se desenrola a partir de um esquema básico, porém não aplicado rigorosamente, permitindo que o entrevistador faça as adaptações que achar conveniente (LÜDKE, 1986, p. $34)$.

Para fins de aplicação desta monografia, foi utilizada a entrevista semi-estruturada por seguir um roteiro que não impede a formulação de outras perguntas durante a entrevista. Além disso, conforme citado por Lüdke (1986, p. 34), “... o tipo de entrevista mais adequado para o trabalho de pesquisa que se faz atualmente [...] aproxima-se mais dos esquemas mais livres, menos estruturados”. 
Conforme descrevem Freitas et al. (2000, p. 105), “os métodos de pesquisa podem ser quantitativos (survey, experimento, etc.) ou qualitativos (estudo de caso, focus group, etc.), devendo sua escolha estar associada aos objetivos da pesquisa”.

A palavra survey significa “levantamento de dados” e é definida por Fink e Kosecoff (1985, p. 13 apud GÜNTHER, 1996, p. 387) como um “método para coletar informações de pessoas acerca das suas idéias, sentimentos, planos, crenças, bem como origens social, educacional e financeira”.

Para Günter (1996), o survey é aplicado às mais diversas áreas das ciências sociais, tendo como instrumento para coleta de dados o questionário, podendo ser administrado tanto em interação pessoal - na forma de entrevista pessoal ou por via telefônica - quanto autoaplicado, após envio via correio ou em grupos. Lembra também que a construção de um instrumento de levantamento de dados dependerá “da população-alvo, do tamanho da amostra, dos conceitos a serem explorados, bem como dos recursos disponíveis para a aplicação e processamento do instrumento” (GÜNTHER, 1996, p. 389).

Corroborando com as idéias de Günther (1996), Freitas et al. (2000), também consideram que o questionário é um dos instrumentos que podem ser utilizados para a realização da survey, cujas estratégias de aplicação podem ser a entrevista pessoal, o envio pelo correio, e-mail, etc. O questionário pode ser estruturado com questões fechadas ou com questões abertas, conforme o objetivo da pesquisa e os procedimentos de coleta de dados (FREITAS et al., 2000).

Independentemente do instrumento a ser utilizado para levantamento de dados, Günther (1996) enfatiza que deve ser obedecida uma estrutura básica, qual seja: i) identificação do pesquisador e legitimação dos objetivos de pesquisa; e i) uma estrutura lógica das temáticas apresentadas na coleta de dados.

Neste trabalho foi utilizado um roteiro de entrevistas, composto de duas perguntas abertas, onde os entrevistados puderam responder livremente, e uma fechada, contendo 59 itens para que cada gerente entrevistado indicasse as competências gerenciais consideradas fundamentais para um desempenho de excelência em sua área de atuação.

As questões elaboradas, conforme Roteiro de Entrevistas no apêndice “A”, procuraram levantar dados sobre os seguintes aspectos:

1. Competências profissionais relevantes para exercer satisfatoriamente as funções na instituição e assim contribuir para a consecução dos objetivos organizacionais;

2. Competências necessárias para uma atuação mais competente;

3. O que caracteriza um gerente competente; 
4. Dados gerais dos entrevistados (caracterização da área em questão; tempo de serviço; formação e função/cargo do profissional).

Assim, o instrumento buscou captar as informações necessárias, por meio de percepções, expectativas e sugestões dos gerentes da área-meio de uma instituição federal de ensino superior quanto às competências necessárias ao cumprimento dos objetivos estratégicos estabelecidos no PDI.

\section{4 - Procedimentos de coleta de dados}

Foram apresentados aos gerentes, no início das entrevistas, o conceito de competência organizacional, de Prahalad (1999) e Prahalad e Hamel (2005) como sendo o conjunto de habilidades e tecnologias que habilitam uma companhia a proporcionar um benefício particular para os clientes, e o conceito de competência individual ou humana, definida por Durand (1998; 2000 apud BRANDÃO; GUIMARÃES, 2001), como sendo o conjunto de conhecimentos, habilidade e atitudes que o indivíduo detém.

Para o levantamento dos dados foi utilizado o roteiro de entrevista, e a forma de registro dos dados foi a gravação direta, pois “tem a vantagem de registrar todas as expressões orais, imediatamente, deixando o entrevistador livre para prestar toda a sua atenção ao entrevistado” (LÜDKE, 1986, p. 37). Para isso, foi requerida autorização do entrevistado para que a entrevista fosse gravada, de modo que as respostas obtidas fossem posteriormente transcritas e analisadas.

Durante as entrevistas, houve um espaço aberto para outras respostas que os respondentes achassem relevantes, porém os pesquisados não fizeram nenhuma outra observação, relacionadas ao presente trabalho, além das solicitadas. Os dados coletados subsidiaram a construção de um painel de competências gerenciais.

\section{5 - Análise dos dados}

Foi realizada uma análise dos dados coletados nas entrevistas, para subsidiar a construção do painel de competências gerenciais, de forma que expressaram as percepções, expectativas e sugestões dos gerentes da área-meio de uma instituição federal de ensino 
superior quanto às competências necessárias ao cumprimento dos objetivos estratégicos estabelecidos.

Assim, com a análise das respostas dos entrevistados e com base na literatura estudada, bem como na análise documental da instituição em estudo, identificaram-se as competências comuns dos profissionais selecionados, relevantes ao cumprimento dos objetivos estratégicos de uma instituição.

Analisar os dados coletados por meio da pesquisa survey é uma tarefa que requer conhecimento profundo dos dados, tempo disponível e muito cuidado na interpretação dos mesmos. Segundo Freitas et al. (2000), uma pesquisa bem estruturada deve permitir que, de posse das ferramentas apropriadas, se chegue com tempo hábil e com energia à exploração dos dados, o que nem sempre acontece. Além disso, "não pode haver equívoco: para se obter algo bom nos dados, deve-se conhecê-los a fundo e dedicar tempo a essa tarefa” (FREITAS et al., 2000, p. 109).

Assim, para se obter resultados confiáveis, os dados

[...] devem ser analisados por meio de ferramental estatístico para a obtenção das informações desejadas, devendo-se, para tanto, considerar o tipo de análise estatística aplicável às variáveis em estudo. As variáveis podem ser qualitativas (por exemplo, sexo) ou quantitativas, que têm como resultado números de determinada escala (por exemplo, tempo de serviço) (FREITAS et al., 2000, p.109).

Quanto às técnicas aplicadas para tabulação dos dados foram utilizados os recursos do aplicativo Microsoft Excel 2000. Foi realizada uma análise descritiva dos dados: freqüência e média. 


\section{4 - Resultados}

A organização estudada é uma instituição federal de ensino superior, criada por lei federal com a finalidade de difundir o ensino, a pesquisa e a extensão, integrados na formação de cidadãos qualificados para o exercício profissional e empenhados na busca de soluções democráticas para os problemas nacionais.

A comunidade é constituída por docentes, discentes e técnico-administrativos, diversificados em suas atribuições e funções, unidos na realização das finalidades da instituição.

Os papéis sociais, os relacionamentos estruturais, as responsabilidades individuais, os limites de autoridade e os requisitos exigidos dos membros da comunidade, bem como os seus direitos, são pautados nos princípios e nas finalidades expressos no Estatuto, definidos no Regimento Geral e no Código de Ética da instituição.

A estrutura organizacional tem característica vertical e vigora desde 1985, revelandose inadequada ao volume e à diversidade das atividades desenvolvidas (MIRANDA, 2005).

As funções gerenciais são classificadas em: Cargos de Direção (CD), que variam de 1 a 4, voltados para a alta gerência, cujas funções são estratégicas para a instituição e Funções Gratificadas (FG), que identificam as gerências intermediárias em seis níveis hierárquicos de acordo com a estrutura, complexidade e responsabilidade de cada unidade administrativa. No estudo em questão, em se tratando da atividade-meio, o foco se deu nas CD’s 3 e 4 e nas seis FG’s, resultando na abrangência de oito níveis hierárquicos (duas CD’s e seis FG’s).

A Tabela 1 apresenta a função e o nível hierárquico dos respondentes.

\begin{tabular}{c|l|c}
\hline Nível & \multicolumn{1}{|c|}{ Função dos respondentes } & Total \\
\hline 1 & Pró-Reitor de Administração & 1 \\
\hline 2 & Diretor & 6 \\
\hline 2 & Assessor de Administração Superior & 1 \\
\hline 2 & Secretário de Gestão Patrimonial & 1 \\
\hline 3 & Gerente 1 & 3 \\
\hline 4 & Gerente 2 - Coordenador de Obras & 1 \\
\hline 4 & Gerente 2 - Coordenador de Projetos & 1 \\
\hline 5 & Gerente 3 & 1 \\
\hline 6 & Gerente 4 & 1 \\
\hline 7 & Gerente 5 - Coordenador de Orçamento e Finanças & 1 \\
\hline 8 & Gerente 6 - Coordenador de Finanças & 18 \\
\hline
\end{tabular}

Tabela 1 - Nível hierárquico e função dos respondentes

Fonte: Entrevista com os gerentes 
A descrição das funções gerenciais ficou assim caracterizada:

1. Pró-Reitor de Administração - Órgão máximo da área-meio da instituição. É responsável pela administração da atividade-meio da instituição - nível 1;

2. Diretor - Função de nível 2, alocada no segundo nível na hierarquia da estrutura organizacional da instituição e incluiu: Diretoria de Desenvolvimento Social (DDS/DAC); Diretoria do Centro de Planejamento (Ceplan); Diretoria de Contabilidade e Finanças (DCF); Diretoria de Obras (DOB/PRC); Diretoria de Orçamento (DOR/DAF) e Diretoria de Recursos Materiais (DRM);

3. Assessor de Administração Superior - com apenas um respondente, essa função é também do nível 2 e abrange atividades voltadas para planejamento, organização, controle e coordenação de atividade-meio e com locação no órgão máximo da instituição;

4. Secretário de Gestão Patrimonial - responsável pela gestão do patrimônio imobiliário da instituição, é também uma função de nível 2 na escala hierárquica da organização;

5. Gerente 1 - Função de nível 3 na hierarquia da estrutura organizacional da instituição e incluiu: Gerente Comercial da Editora da UnB (CML/EDU); Gerente de Execução Orçamentária da Diretoria de Contabilidade e Finanças (SEO/DCF); Gerente de Pós-Graduação da Diretoria de Administração Acadêmica (DAA);

6. Gerente 2 - Função de nível 4 na hierarquia da estrutura organizacional da instituição e incluiu: Coordenador de Projetos, responsável pela elaboração dos projetos arquitetônicos e complementares de instalação e estrutura das obras de propriedade da instituição; Coordenador de Obras, responsável pela execução e fiscalização das obras de propriedade da instituição;

7. Gerente 3 - Função de nível 5, incluiu a Gerência de Desenvolvimento de Recursos Humanos da Secretaria de Recursos Humanos (SRH);

8. Gerente 4 - Gerente de Unidades Avançadas da Diretoria de Administração Acadêmica (DAA), correspondente ao nível 6;

9. Gerente 5 - Coordenador de Orçamento e Finanças do Centro de Planejamento Oscar Niemeyer (CEPLAN), correspondente ao nível 7;

10. Gerente 6 - Coordenador de Finanças do Centro de Apoio ao Desenvolvimento Tecnológico (CDT), correspondente ao nível 8. 
Para a análise dos dados referentes à primeira pergunta da entrevista, cuja questão foi “o que possibilita que você seja competente na sua atuação como gerente?”, procedeu-se ao agrupamento dos itens de acordo com o que cada respondente falou espontaneamente, o que é demonstrado na Tabela 2.

\begin{tabular}{|c|c|c|}
\hline Competências Gerenciais & $\begin{array}{l}\text { Número de } \\
\text { incidências }\end{array}$ & $\%$ \\
\hline Conhecimento do trabalho & 12 & 66,67 \\
\hline Conhecimento/Aplicação da legislação pertinente à área de atuação & 10 & 55,56 \\
\hline Conhecimento da estrutura organizacional & 8 & 44,44 \\
\hline Conhecimento da instituição & 8 & 44,44 \\
\hline Relacionamento interpessoal & 8 & 44,44 \\
\hline Articulação (interna e externa) & 7 & 38,89 \\
\hline Compromisso com a instituição & 7 & 38,89 \\
\hline Experiência profissional & 7 & 38,89 \\
\hline Foco em processos e em resultados & 7 & 38,89 \\
\hline Trabalho em equipe & 7 & 38,89 \\
\hline Capacitação dos membros da equipe & 5 & 27,78 \\
\hline Responsabilidade & 5 & 27,78 \\
\hline Apoio da alta administração & 4 & 22,22 \\
\hline Formação compatível com a função & 4 & 22,22 \\
\hline Recursos disponíveis & 4 & 22,20 \\
\hline Articulação (interna e externa) & 3 & 16,67 \\
\hline Atualização acerca dos assuntos da área de atuação & 3 & 16,67 \\
\hline Administração de conflitos & 2 & 11,10 \\
\hline Confiança nos membros da equipe & 2 & 11,10 \\
\hline Conhecimento das competências dos membros da equipe & 2 & 11,10 \\
\hline Conhecimento do planejamento estratégico da instituição & 2 & 11,10 \\
\hline Conhecimento/Aplicação do orçamento público & 2 & 11,10 \\
\hline Delegação de competências & 2 & 11,10 \\
\hline Melhoria das instalações físicas & 2 & 11,10 \\
\hline Motivação da equipe & 2 & 11,10 \\
\hline Organização & 2 & 11,10 \\
\hline Proatividade & 2 & 11,10 \\
\hline Adaptação a situações novas & 1 & 5,56 \\
\hline Capacidade gerencial & 1 & 5,56 \\
\hline Colaboração & 1 & 5,56 \\
\hline Compatibilidade com o programa estabelecido pela Administração & 1 & 5,56 \\
\hline \multicolumn{3}{|c|}{ continua } \\
\hline
\end{tabular}




\begin{tabular}{l|c|c}
\hline Competências Gerenciais & $\begin{array}{c}\text { Número de } \\
\text { incidências }\end{array}$ & \% \\
\hline Comunicação (oral e escrita) & 1 & 5,56 \\
\hline Conhecimento da missão e dos valores da instituição & 1 & 5,56 \\
\hline Conhecimento/Aplicação da Gestão de Pessoas & 1 & 5,56 \\
\hline Conhecimento/Aplicação da gestão do conhecimento & 1 & 5,56 \\
\hline Conhecimento/Aplicação da Tecnologia da Informação & 1 & 5,56 \\
\hline Conhecimento/Aplicação dos recursos de informática & 1 & 5,56 \\
\hline Cumprimento dos prazos estabelecidos & 1 & 5,56 \\
\hline Disciplina & 1 & 5,56 \\
\hline Disponibilidade para feedback ao superior imediato & 1 & 5,56 \\
\hline Humildade & 1 & 5,56 \\
\hline Liderança & 1 & 5,56 \\
\hline Negociação & 1 & 5,56 \\
\hline Noçães de Administração, contabilidade e economia & 1 & 5,56 \\
\hline Planejamento & 1 & 5,56 \\
\hline Visão estratégica & 1 & 5,56 \\
\hline
\end{tabular}

Tabela 2 - Competências gerenciais informadas pelos respondentes na questão 1

Fonte: Entrevista com os gerentes

Nota: A soma das freqüências é superior a 100\% por ter sido possível aos entrevistados darem mais de uma resposta. O percentual foi calculado em relação ao número de pesquisados (18).

Alguns aspectos informados na questão 1 não são considerados pela literatura como competências gerenciais, mas dizem respeito à infra-estrutura organizacional: recursos disponíveis e melhoria das instalações físicas. Esses aspectos também podem influenciar um desempenho competente, uma vez que dão suporte para execução eficaz das tarefas a serem realizadas (BRANDÃO; GUIMARÃES, 2001).

Aspectos como “colaboração” e "humildade” chamaram a atenção por terem sido informados apenas uma vez. Esses aspectos não foram encontrados na literatura como competências gerenciais, mas sim como atitudes associadas ao trabalho em equipe. Não se pôde encontrar na literatura uma explicação para que tais aspectos fossem apresentados, mesmo que por apenas um dos entrevistados. O que se pode constatar é que deveria ser perguntado a esse respondente porque esses aspectos são importantes para sua atuação como gerente.

O aspecto "visão estratégica" chamou atenção por ter sido informada por uma área considerada não estratégica, porém de fundamental importância, pois se trata de uma unidade cujas atividades devem estar alinhadas às ações estratégicas da instituição. Trata-se da 
gerência de desenvolvimento de pessoas, responsável pelo estabelecimento de políticas na área de gestão de pessoas da instituição.

Para a pergunta número 2, também aberta, sobre "o que permitiria que você se tornasse mais competente na sua atuação como gerente?”, obtiveram-se os seguintes aspectos, apresentados na Tabela 3.

\begin{tabular}{l|c|c}
\hline Competências Gerenciais & $\begin{array}{c}\text { Número de } \\
\text { incidências }\end{array}$ & \% \\
\hline Capacitação dos membros da equipe & 16 & 88,88 \\
\hline Ampliação do quadro de pessoal & 13 & 72,22 \\
\hline Negociação & 11 & 61,11 \\
\hline Remuneração compatível & 10 & 55,56 \\
\hline Autonomia & 8 & 44,44 \\
\hline Recursos disponíveis & 7 & 38,89 \\
\hline Foco em processos & 6 & 33,33 \\
\hline Melhoria das instalações físicas & 6 & 33,33 \\
\hline Modernização dos equipamentos/softwares de informática & 5 & 27,78 \\
\hline Comprometimento dos membros da equipe & 3 & 16,67 \\
\hline Cumprimento dos prazos estabelecidos & 3 & 16,67 \\
\hline Articulação interna & 1 & 5,56 \\
\hline Clareza na definição dos objetivos e metas da instituição & 1 & 5,56 \\
\hline Cumprimentos das normas internas & 1 & 5,56 \\
\hline Formação compatível dos membros da equipe com as funções exercidas & 1 & 5,56 \\
\hline Implantação de um sistema de gerenciamento das informações & 1 & 5,56 \\
\hline Melhoria das condiçães de trabalho & 1 & 5,56 \\
\hline Melhoria das rotinas de trabalho & 1 & 5,56 \\
\hline Organização & 1 & 5,56 \\
\hline Planejamento & 1 & 5,56 \\
\hline Programa de lazer para integração dos membros da equipe & 1 & 5,56 \\
\hline Reconhecimento do trabalho por parte da alta administração & 5,56 \\
\hline Relacionamento interpessoal & 1 & 5,56 \\
\hline Respeito ao calendário de atividades internas & 1 & 5,56 \\
\hline Reuniões periódicas de avaliação de desempenho da equipe & 5,56 \\
\hline Tomada de decisão & 1 & 5,56 \\
\hline Tabe & 1 & \\
\hline
\end{tabular}

Tabela 3 - Competências gerenciais informadas pelos respondentes na questão 2

Fonte: Entrevista com os gerentes

Nota: A soma das freqüências é superior a 100\% por ter sido possível aos entrevistados darem mais de uma resposta. O percentual foi calculado em relação ao número de pesquisados (18). 
Assim como na Tabela 2, aspectos como "recursos disponíveis”, "melhoria das instalações físicas” e "modernização dos equipamentos/softwares de informática”, foram informados na Tabela 3 como sendo competências gerenciais, porém estão mais diretamente relacionados à infra-estrutura organizacional e às condições ambientais necessárias ao bom desempenho no trabalho. Esses aspectos podem influenciar um desempenho competente, uma vez que dão suporte para execução eficaz das tarefas a serem realizadas. Por outro lado, considerando a corrente da gestão de competências, Brandão e Guimarães (2001, p. 13) afirmam que "a competência humana, aliada a outros recursos, dá origem e sustentação à competência organizacional”.

Aspectos apontados com maior incidência são voltados para características que dizem respeito aos processos de trabalho, como condição inerente ao bom desenvolvimento das atividades gerenciais: capacitação dos membros da equipe. ampliação do quadro de pessoal, negociação, remuneração compatível, autonomia, foco em processos.

Como se tratam de perguntas abertas pode ser que os respondentes tenham se sentido mais à vontade para expor aspectos não ligados diretamente ao seu desempenho profissional, mas que, de alguma forma, influenciam esse desempenho, uma vez que, segundo Carbone et al. (2005, p. 56) a competência "representa um desempenho ou comportamento esperado, indicando o que o profissional deve ser capaz de fazer”. Para isso, as condições ambientais e um suporte organizacional para a execução eficaz da tarefa são aspectos fundamentais para que o indivíduo obtenha um desempenho eficaz (ABAD; FREITAS; PILATI, 2005).

Analisando-se ainda os níveis dos respondentes, verificou-se que apenas os gerentes intermediários (detentores de FG's) apontaram esses aspectos como fundamentais para um desempenho de excelência, indicando que nesse nível de gerência as condições ambientais e os suportes necessários ainda não são adequados para o que desejam.

Outro ponto a se considerar é que as perguntas não focaram especificamente as competências e sim “o que possibilita” e “o que permitiria” que os gerentes se tornassem competentes, deixando assim abertura à abordagem de outros aspectos além dos associados a competências.

A pergunta número 3 foi do tipo "fechada” em que foi apresentada uma lista com 59 competências gerenciais, onde os respondentes tiveram que escolher entre as opções "sim” ou “não" em cada conhecimento, habilidade e atitude apresentados que consideraram fundamentais para um desempenho de excelência na sua área de atuação, conforme demonstrados na Tabela 4. 


\begin{tabular}{|c|c|c|}
\hline Competências Gerenciais & $\begin{array}{l}\text { Número de } \\
\text { incidências }\end{array}$ & $\%$ \\
\hline Conhecimento do Regimento Interno & 18 & 100,00 \\
\hline Conhecimento da legislação específica & 18 & 100,00 \\
\hline Planejamento do trabalho & 18 & 100,00 \\
\hline Organização do trabalho & 18 & 100,00 \\
\hline Recursos disponíveis & 18 & 100,00 \\
\hline Trabalho em equipe & 18 & 100,00 \\
\hline Criatividade & 18 & 100,00 \\
\hline Ética & 18 & 100,00 \\
\hline Visão sistêmica & 18 & 100,00 \\
\hline Comprometimento com os interesses da instituição & 18 & 100,00 \\
\hline Liderança & 18 & 100,00 \\
\hline Raciocínio lógico & 18 & 100,00 \\
\hline Conhecimento do trabalho & 18 & 100,00 \\
\hline Conhecimento das competências dos membros da equipe & 18 & 100,00 \\
\hline Assertividade & 18 & 100,00 \\
\hline Responsabilidade & 18 & 100,00 \\
\hline Disciplina & 18 & 100,00 \\
\hline Transparência & 18 & 100,00 \\
\hline Aplicação da legislação específica & 17 & 94,44 \\
\hline Cumprimento dos prazos estabelecidos & 17 & 94,44 \\
\hline Visão estratégica & 17 & 94,44 \\
\hline Relacionamento interpessoal & 17 & 94,44 \\
\hline Inovação & 17 & 94,44 \\
\hline Articulação interna & 17 & 94,44 \\
\hline Autodesenvolvimento & 17 & 94,44 \\
\hline Adaptação a situações novas & 17 & 94,44 \\
\hline Conhecimento da Gestão de Pessoas & 17 & 94,44 \\
\hline Aplicação dos conhecimentos sobre Gestão de Pessoas & 17 & 94,44 \\
\hline Gestão do conhecimento & 17 & 94,44 \\
\hline Relacionamento com outras áreas & 17 & 94,44 \\
\hline Tomada de decisão & 16 & 88,89 \\
\hline Negociação & 16 & 88,89 \\
\hline Conhecimento da missão e dos valores da instituição & 16 & 88,89 \\
\hline Conhecimento da estrutura organizacional & 16 & 88,89 \\
\hline Conhecimento do Planejamento Estratégico da instituição & 16 & 88,89 \\
\hline
\end{tabular}




\begin{tabular}{l|c|c}
\hline Competências Gerenciais & $\begin{array}{c}\text { Número de } \\
\text { incidências }\end{array}$ & \% \\
\hline Conhecimento dos recursos da informática & 16 & 88,89 \\
\hline Absorção de conhecimentos & 16 & 88,89 \\
\hline Comunicação escrita & 16 & 88,89 \\
\hline Foco em processos & 16 & 88,89 \\
\hline Foco em resultados & 16 & 88,89 \\
\hline Proatividade & 16 & 88,89 \\
\hline Interação com outras áreas & 16 & 88,89 \\
\hline Atualização acerca das novas tecnologias & 15 & 83,33 \\
\hline Transferência de conhecimentos & 15 & 83,33 \\
\hline Discrição & 15 & 83,33 \\
\hline Raciocínio conceitual & 15 & 83,33 \\
\hline Articulação externa & 14 & 77,78 \\
\hline Conhecimento do orçamento público & 14 & 77,78 \\
\hline Raciocínio numérico & 14 & 77,78 \\
\hline Conhecimento das atividades de outras áreas & 14 & 77,78 \\
\hline Formação profissional compatível com a função & 13 & 72,22 \\
\hline Julgamento & 13 & 72,22 \\
\hline Aplicação dos conhecimentos dos recursos da informática & 13 & 72,22 \\
\hline Comunicação oral & 11 & 61,11 \\
\hline Elaboração de editais, portarias, relatórios diversos & 9 & 55,56 \\
\hline Aplicação dos conhecimentos sobre orçamento público & 80,00 \\
\hline Conhecimento do Estatuto & 7 & 44,44 \\
\hline Pensamento abstrato & 4 & 38,89 \\
\hline Conhecimento de pesquisa & 22,22 \\
\hline Tabea 4- Coma & 13 \\
\hline
\end{tabular}

Tabela 4 - Competências gerenciais apontadas pelos respondentes na questão 3

Fonte: Entrevista com os gerentes

Nota: A soma das frequiências é superior a $100 \%$ por ter sido possível aos entrevistados darem mais de uma resposta. O percentual foi calculado em relação ao número de pesquisados (18).

Analisando-se os aspectos apontados na questão 3, conforme Tabela 4, verificou-se uma uniformidade nas competências identificadas independentemente da área, do nível hierárquico e da função dos respondentes. Dezoito aspectos, correspondentes a $30 \%$ dos indicadores, foram considerados por 100\% dos respondentes como fundamentais para um desempenho de excelência na área de atuação de cada gerente. Doze aspectos, correspondente a $20 \%$ dos indicadores, foram considerados relevantes por $94,44 \%$ dos respondentes, enquanto dezesseis aspectos, correspondentes a $27 \%$ dos indicadores, foram apontados como relevantes para 88,89\% dos respondentes. Quatro aspectos, correspondentes a 6,78\% dos 
indicadores, foram respondidos por 77,22\% dos respondentes como relevantes. Três aspectos (5,08\%) foram apontados por 72,2\%. Esse alto percentual de incidências indica que uma uniformidade em relação à opinião dos pesquisados quanto às competências necessárias ao desenvolvimento do seu trabalho.

Comparando os itens descritos na questão 1 e 2 com os listados na questão 3, foram identificados os seguintes aspectos adicionais:

Administrar conflitos;

$>$ Conhecimento e aplicação da tecnologia da informação;

> Apoio da alta administração;

Autonomia;

$>$ Confiança nos membros da equipe;

$>$ Delegação de tarefas;

$>$ Capacitação continuada.

Nas entrevistas e em manifestações informais, quando espontaneamente falaram das suas atividades rotineiras, os respondentes apontaram aspectos que parecem indicar: i) uma necessidade de combater a insatisfação dos gerentes diante das políticas públicas; ii) a falta de reconhecimento dos trabalhos por parte da administração superior; ii) uma demanda por capacitação profissional visando ao acompanhamento das exigências do mercado; iv) agilidade nas etapas do trabalho visando à velocidade na tramitação dos processos administrativos.

O resultado da comparação entre as competências informadas de modo espontâneo nas questões 1 e 2 (Tabelas 2 e 3) e a partir da lista de competências da questão 3 (Tabela 4), apresenta-se na Tabela 5, que demonstra apenas os indicadores não citados pelos respondentes nas questões anteriores e que foram apontados na questão 3.

\begin{tabular}{l|c|c}
\hline Competências Gerenciais & $\begin{array}{c}\text { Número de } \\
\text { incidências }\end{array}$ & $\mathbf{\%}$ \\
\hline Assertividade & 18 & 100,00 \\
\hline Ética & 18 & 100,00 \\
\hline Raciocínio lógico & 18 & 100,00 \\
\hline Transparência & 18 & 100,00 \\
\hline Visão sistêmica & 18 & 100,00 \\
\hline Autodesenvolvimento & 17 & 94,44 \\
\hline Inovação & 17 & 94,44 \\
\hline & & continua \\
\hline
\end{tabular}




\begin{tabular}{l|c|c}
\hline Competências Gerenciais & $\begin{array}{c}\text { Número de } \\
\text { incidências }\end{array}$ & $\mathbf{\%}$ \\
\hline Relacionamento com outras áreas & 17 & 94,44 \\
\hline Absorção de conhecimentos & 16 & 88,89 \\
\hline Interação com outras áreas & 16 & 88,89 \\
\hline Atualização acerca das novas tecnologias & 15 & 83,33 \\
\hline Discrição & 15 & 83,33 \\
\hline Raciocínio conceitual & 15 & 83,33 \\
\hline Transferência de conhecimentos & 15 & 83,33 \\
\hline Conhecimento das atividades de outras áreas & 14 & 77,78 \\
\hline Raciocínio numérico & 14 & 77,78 \\
\hline Julgamento & 13 & 72,22 \\
\hline Elaboração de editais, portarias, relatórios diversos, etc. & 10 & 55,56 \\
\hline Conhecimento do Estatuto da instituição & 8 & 44,44 \\
\hline Pensamento abstrato & 7 & 38,89 \\
\hline Conhecimento de pesquisa & 4 & 22,22 \\
\hline
\end{tabular}

Tabela 5 - Competências não informadas nas questões 1 e 2 e apontadas na questão 3 Fonte: Entrevista com os gerentes

Nota: A soma das freqüências é superior a 100\% por ter sido possível aos entrevistados darem mais de uma resposta. O percentual foi calculado em relação ao número de pesquisados (18).

É importante ressaltar que a lista de competências contidas na questão 3 somente foi mostrada aos respondentes após as manifestações espontâneas às questões 1 e 2. Assim, parece que esses aspectos foram lembrados pelos respondentes apenas após estarem listados.

A elaboração da lista permitiu então identificar aspectos como assertividade, ética, raciocínio lógico, transparência e visão sistêmica, considerados relevantes para um desempenho de excelência na área de atuação de todos os gerentes entrevistados. Outros aspectos também tiveram um alto grau de importância, ratificando que existem competências que são comuns aos vários gerentes.

Comparando-se as questões abertas (1 e 2) com a questão fechada (3), constatou-se que alguns aspectos tiveram uma incidência mínima nas questões abertas enquanto na questão 3 tiveram uma grande incidência, conforme apresentado na Tabela 6.

Uma possível explicação para essa diferença é a não familiaridade dos gerentes com as terminologias utilizadas para designar as competências inerentes ao cargo que ocupam, enquanto que, quando lhes é apresentada uma tabela com uma lista de competências gerenciais, esses aspectos são lembrados como conhecimentos, habilidade e atitudes relevantes às suas atividades. 


\begin{tabular}{l|c|c}
\hline \multirow{2}{*}{\multicolumn{1}{c|}{ Competências Gerenciais }} & \multicolumn{2}{c}{ Número de incidências } \\
\cline { 2 - 3 } & Questões 1 e 2 & Questão 3 \\
\hline Disciplina & 1 & 18 \\
\hline Planejamento & 1 & 18 \\
\hline Liderança & 1 & 18 \\
\hline Adaptação a situações novas & 1 & 17 \\
\hline Tomada de decisão & 1 & 16 \\
\hline Proatividade & 2 & 16 \\
\hline
\end{tabular}

Tabela 6 - Comparação entre competências das questões 1 e 2 com a questão 3

Fonte: Entrevista com os gerentes

A seguir serão discutidos os resultados apresentados nas entrevistas fazendo-se comparação com os resultados encontrados na literatura da área. 


\section{5 - Discussão dos resultados}

As atividades gerenciais no contexto de modernização do Estado brasileiro, de transformações organizacionais, ajustes e desajustes de funções, responsabilidades e papéis, exigem cada vez mais o desenvolvimento de competências gerenciais e a reflexão sobre aspectos ligados ao controle, à pós-modernidade, ao setor público, ao simbolismo intenso, à vida familiar, à aprendizagem constante, ao estresse e à identidade (DAVEL; MELO, 2005).

A literatura indica também que competências como administrar conflitos e estar preparado às pressões do dia-a-dia tem sido o grande desafio para os gerentes, pois cabe a eles a difícil missão de fazer a gestão de pessoas, lidando com interesses divergentes, para trabalharem em equipe, visando ao atingimento dos resultados organizacionais.

Para Marra e Melo (2005), reconhecer as diferenças culturais entre as organizações e compreender a cultura e a realidade do contexto em que está inserido, são aspectos cruciais ao sucesso das práticas gerenciais. Nesse sentido, Leonard-Barton (1998, p. 291) afirma que "ao reconhecer diferentes tipos de cultura, o gerente amplia sua capacidade de reagir adequadamente”.

Segundo Davel e Melo (2005, p. 135), algumas práticas formais instituídas pelas empresas se impõem às ações dos gerentes, fazendo com que estes "não passem de simples agentes de ordens imperativas, geradas externamente às práticas sociais de seus cotidianos”. Para minimizar essa situação, Zarifian (1999) descreveu como um desafio para os órgãos públicos assumir um papel "qualificante" no sentido de dar suporte às iniciativas de capacitação profissional, criar um ambiente favorável à aprendizagem e oferecer reais oportunidades de crescimento profissional aos seus servidores.

Aspectos como "pensamento abstrato" e "conhecimento de pesquisa” foram citados por um pequeno número de respondentes que são responsáveis pelo estabelecimento dos objetivos estratégicos da instituição.

Comparando-se os aspectos informados nas entrevistas com os encontrados na literatura da área, e com base na análise de conteúdo e documental, foram verificadas semelhanças nas competências gerenciais identificadas na pesquisa da instituição em estudo.

Assim, para os fins a que se propôs este trabalho, elaborou-se um painel de competências relevantes aos gerentes da atividade-meio da instituição em estudo e com base nas três dimensões que apóiam o conceito de competência definidas por Durand (1998 apud BRANDÃO; GUIMARÃES, 2002), associou-se as competências gerenciais em conhecimentos, habilidades e atitudes, apresentadas no Quadro 5. 


\begin{tabular}{|l|l|}
\hline \multicolumn{1}{|c|}{ CHA's } & \multicolumn{1}{c|}{ Competências gerenciais } \\
\hline Conhecimentos & $>$ Conhecimento da missão e dos valores da instituição \\
& $>$ Conhecimento das competências dos membros da equipe \\
& $>$ Conhecimento do Regimento Interno \\
& $>$ Conhecimento do trabalho \\
& $>$ Conhecimento dos recursos da informática \\
& $>$ Recursos disponíveis \\
& $>$ Visão estratégica \\
& $>$ Visão sistêmica \\
& $>$ Adaptação a situações novas \\
& $>$ Aplicação dos conhecimentos dos recursos da informática \\
& $>$ Aplicação dos conhecimentos sobre orçamento público \\
& $>$ Comunicação escrita \\
& $>$ Comunicação oral \\
& $>$ Criatividade \\
& $>$ Elaboração de editais, portarias, relatórios diversos \\
& $>$ Foco em processos \\
& $>$ Foco em resultados \\
& $>$ Gestão do conhecimento \\
& $>$ Inovação \\
& $>$ Liderança \\
& $>$ Negociação \\
& $>$ Organização do trabalho \\
& $>$ Planejamento do trabalho \\
& $>$ Relacionamento interpessoal \\
& $>$ Trabalho em equipe \\
& $>$ Articulação externa \\
& $>$ Atualização acerca das novas tecnologias \\
& $>$ Comprometimento com os interesses da instituição \\
\hline & Respilidade \\
\hline Atitudes & \\
&
\end{tabular}

Quadro 5 - Competências gerenciais sugeridas

Fonte: Entrevista com os gerentes

Os resultados mostraram que as competências indicadas por todos os gerentes, consideradas relevantes ao desenvolvimento das atividades em cada área de atuação, foram: o conhecimento do trabalho, da legislação pertinente à área de atuação, do orçamento público; planejamento e organização do trabalho; trabalho em equipe; criatividade; ética, visão 
sistêmica; liderança; raciocínio lógico; responsabilidade; transparências nos atos e comprometimento com os interesses da instituição.

Esses resultados indicam uma predominância em aspectos diretamente relacionados à dimensão do “saber fazer” (habilidades), o que, segundo Kilimnik, Sant’anna e Luz (2005), apontam para a necessidade de se favorecer um ambiente organizacional que contribua efetivamente para que as pessoas consigam desenvolver as competências necessárias para atingir resultados e lidar com situações novas no contexto em que estão inseridas. Nesse sentido, Davel e Melo (2005, p. 271) afirmam que "não se pode pensar em transmitir competências, pois elas não são transferíveis, mas sim em criar condições favoráveis para a construção pessoal das competências”.

Observou-se, também, uma grande incidência em aspectos relativos ao planejamento e organização do trabalho, conhecimento do trabalho, criatividade, relacionamento interpessoal e trabalho em equipe, entre outras dessa natureza, o que indica uma demanda pelas competências descritas por Aubrum e Orofiamma (1991 apud Kilimnik; Sant’anna; Luz, 2005) como de terceira dimensão, caracterizadas como qualidades pessoais e relacionais, essenciais ao trabalho em equipe.

Esses aspectos são extremamente importantes nas atividades dos gerentes, pois, caso contrário, segundo Davel e Melo (2005, p. 150), “o planejamento dá lugar ao apaga incêndio, mais próximo da aventura do que do alcance de fins predefinidos, imperando a criatividade e a improvisação”.

Encontrou-se ainda uma elevada incidência de aspectos relacionados à cultura e aos valores da instituição, com destaque para: conhecimento do regimento interno (100\%), comprometimento com os interesses da instituição (100\%), trabalho em equipe (100\%), conhecimentos da missão e dos valores da instituição (88,89\%), da estrutura organizacional (88,89\%) e do planejamento estratégico da instituição (88,89\%). Essa evidência ratifica as recomendações de Brandão e Bahry (2005) para os quais a adoção de uma lista de competências deve estar sintonizada com o contexto e alinhada à estratégia organizacional. Assim, para Brandão e Bahry (2005, p. 192) “cada organização tem suas particularidades, sua cultura, estrutura e estratégia, entre outros elementos, que a distinguem das demais, o que exige a definição de rol de competências contextualizado e adequado às suas necessidades específicas".

Percebeu-se, também, uma necessidade premente de mudança no perfil de alguns gerentes quando de suas manifestações às questões da entrevista. Alguns se mostraram mais burocratas, focando ações mais operacionais e voltadas exclusivamente às normas 
estabelecidas enquanto outros mais pragmáticos, com espírito empreendedor, demonstrando ações estratégicas, de cunho eminentemente gerencial, na busca por melhores interesses de eficiência e eficácia. Para Lotta (2005), as práticas burocráticas evidenciam um possível atraso que a administração pública vem passando ao longo dos anos. "Seja por seu imenso tamanho, ou pelas heranças ainda marcantes, a administração pública mundial passa por lenta transição que traz do passado marcas da ineficiência e improdutividade, representadas por ações voltadas ao cumprimento burocrático de legislação” (LOTTA, 2005, p. 11).

Nesse sentido, para Davel e Melo (2005),

[...] não se pode imaginar um perfil ideal de gerente empreendedor sem que se consiga, depois de levantadas certas práticas recorrentes, construir, juntamente com os próprios ocupantes das funções gerenciais no setor público, novas práticas sociais de gestão, tendo em vista que tais atores estão bem distantes do tipo ideal weberiano - o burocrata impessoal -, como de sua antítese - o gerente empreendedor -, característico da administração pública gerencial (DAVEL; MELO, 2005, p. 153).

Segundo Lotta (2002, p. 11), “para mudar tal realidade, é necessário que a administração pública volte suas atenções para políticas internas, priorizando ações que dizem respeito a seus funcionários”. Além disso, as funções da área de gestão de pessoas devem ser revistas e repensadas para se adequar à nova realidade. Nesse contexto, conforme enfatiza Lotta (2002), um sistema de avaliação de desempenho eficiente pode ser um instrumento essencial, na medida em que busca identificar as necessidades de mudança.

Para Davel e Melo (2005), as características estruturais da nossa sociedade servem de base para as atividades de gerentes organizacionais, estejam eles no setor público ou no setor privado.

Segundo Davel e Melo (2005),

[...] faz-se mister definir alternativas que possibilitem ações empresariais estratégicas, mais voltadas para as realidades locais, que articulem modelos de gestão portadores de ferramentas referenciais universalmente aplicáveis e que sejam embebidas pelos traços típicos das sociedades em que estão inseridas (DAVEL; MELO, 2005, p. 152).

Assim, nessa mesma linha, Guimarães e Medeiros (2003) destacam que alguns órgãos públicos têm buscado, ainda que timidamente, a implementação da gestão por competências na tentativa de uma gestão mais flexível e empreendedora que tenha como objetivo melhorar a qualidade e a eficiência dos serviços públicos prestados. 


\section{6 - Considerações finais}

Este estudo pôde evidenciar que as competências gerenciais devem estar voltadas à realidade de cada contexto, haja vista as políticas estabelecidas pelo Estado nos órgãos da administração pública federal.

Além disso, as práticas do dia-a-dia demonstram como os gerentes se apropriam dos seus conhecimentos comuns, construídos e legitimados socialmente, para tornar possível a continuidade da rotina da gestão institucional buscando atingir, por meio das pessoas, os objetivos organizacionais.

Entretanto, se faz necessário o estabelecimento de um modelo de gestão voltado para ações (e não apenas a formalização de políticas) internas, com prioridade para a área de gestão de pessoas, adequadas à realidade dos processos de melhoria contínua, visando à qualidade dos bens e serviços produzidos pela administração pública. A implantação de um sistema de desempenho baseado em competências é fundamental para a manutenção da qualidade dos serviços públicos prestados pelo Estado.

Como limitações deste trabalho, registram-se o pequeno grupo que foi entrevistado, uma única instituição pesquisada e o tempo exíguo para sua conclusão. Por outro lado, considerando-se que se trata de um trabalho em nível de pós-graduação Lato Sensu, entendese que foi satisfatório pelos resultados apresentados, pois nenhum dos fatores evidenciados pela pesquisa apresentou conflitos com os elencados na literatura.

Entretanto, muitos dos fatores apresentados variam de autor para autor, indicando a necessidade de pesquisas mais profundas nessa área que permitam confirmar ou refutar os resultados obtidos junto a outros órgãos públicos e em outros contextos. Assim, sugere-se que o mapeamento elencado sirva de subsídio para que seja elaborado um instrumento de pesquisa (sugere-se um questionário) e aplicado em instituições afins.

A literatura indica que as funções básicas dos administradores públicos e privados são praticamente idênticas. Entretanto, os dirigentes das organizações públicas estão submetidos a inúmeras limitações e entraves legais, demandas públicas difíceis de atingir, orçamento limitado, interferências político-partidárias e expectativas fora da realidade que estão inseridos, coisas não inerentes às atividades do setor privado. Isto foi evidenciado na pesquisa, que indicou a necessidade efetiva de os gerentes terem competências que abranjam o conhecimento do contexto e das condições características da administração pública federal.

Para assegurar resultados em organizações da administração pública, e considerando as especificidades apontadas, seria importante o aprofundamento do conhecimento a respeito 
das competências necessárias a esses profissionais, de modo a balizar a seleção de gerentes intermediários entre aqueles com mais capacidade técnica e conhecedores das práticas administrativas e institucionais, e não por critérios políticos. 


\section{REFERÊNCIAS}

ABBAD, G. S.; BORGES-ANDRADE, J. E. Aprendizagem humana em organizações e trabalho. In: ZANELLI, J. C.; BORGES-ANDRADE, J. E.; BASTOS, V. B. (Orgs.).

Psicologia, organizações e trabalho no Brasil. Porto Alegre: Artmed, 2004. cap. 7, p. 237275.

ABBAD, G. S.; FREITAS, I. A.; PILATI, R. Contexto de trabalho, desempenho competente e necessidades em TD\&E. In: BORGES-ANDRADE, J. E.; ABBAD, G. S.; MOURÃO, L. (Orgs.). Treinamento, desenvolvimento e educação em organizações e trabalho. Porto Alegre: Artmed, 2005. cap. 12. (no prelo).

BITENCOURT, C. C. A gestão de competências gerenciais e a contribuição da aprendizagem organizacional: a experiência de três empresas australianas. Revista de Administração Mackenzie (RAM). São Paulo, v. 3, n.1, p. 135-157, 2003.

BORGES-ANDRADE, J. E.; LIMA, S. M. V. Avaliação de necessidades de treinamento: um método de análise ocupacional. Tecnologia educacional, v. 12, n. 54, p. 6-22, 1983.

BRANDÃO, H. P. Gestão baseada nas competências: um estudo sobre competências profissionais na indústria bancária. Brasília. Dissertação (Mestrado em Administração). Universidade de Brasília. 1999.

BRANDÃO, H. P.; BAHRY, C. P. Gestão por competências: métodos e técnicas para mapeamento de competências. Revista do Serviço Público (RSP), Brasília, v. 56, n. 2, p. 179-194, abr./jun., 2005.

BRANDÃO, H. P.; GUIMARÃES, T. A. Gestão de competências e gestão de desempenho: tecnologias distintas ou instrumentos de um mesmo construto? Revista de Administração de Empresas (RAE), São Paulo, v. 41, n. 1, p. 8-15, jan./mar., 2001.

BRANDÃO, H. P.; GUIMARÃES, T. A. Gestão de competências e gestão de desempenho. In: WOOD JR., T. (Coord.). Gestão empresarial: o fator humano. São Paulo. Atlas, 2002. p. 55-70.

BRANDÃO, H. P.; GUIMARÃES, T. A.; BORGES-ANDRADE, J. E. Competências profissionais relevantes à qualidade no atendimento bancário. Revista de Administração Pública (RAP), Rio de Janeiro, v. 35, n. 6, p. 61-81, nov./dez., 2001.

BRESSER PEREIRA, L. C. Uma reforma gerencial da administração pública no Brasil. In: PETRUCCI, V.; SCHWARZ, L. (Org.). Administração pública gerencial: a reforma de 1995: ensaios sobre a reforma administrativa brasileira no limiar do século XXI. Brasília: Universidade de Brasília: ENAP, 1999. Parte I, p. 18-62.

CARBONE, P. P. et al. Gestão por competências e gestão do conhecimento. Rio de Janeiro: FGV, Série Gestão de Pessoas, 2005. 
CARVALHO, O. F. Educação e formação profissional: trabalho e tempo livre. Brasília: Plano, 2003.

DAVEL, E.; MELO, M. C. O. L. (Orgs.). Gerência em ação: singularidades e dilemas do trabalho gerencial. Rio de Janeiro: FGV, 2005.

DE MASI, D. Os fatores da mudança. In: O futuro do trabalho: fadiga e ócio na sociedade pós-industrial. Rio de Janeiro: José Olympio; Brasília: Universidade de Brasília, 1999. cap. 12, p. 175-194.

DUTRA, J. S. Competências: conceitos e instrumentos para a gestão de pessoas na empresa moderna. São Paulo: Atlas, 2004.

FERREIRA, C. M. Crise e reforma do Estado: uma questão de cidadania e valorização do servidor. In: PETRUCCI, V.; SCHWARZ, L. (Org.). Administração pública gerencial: a reforma de 1995: ensaios sobre a reforma administrativa brasileira no limiar do século XXI. Brasília: Universidade de Brasília: ENAP, 1999. Parte I, p. 63-95.

FLEURY, M. T. L.; FLEURY, A. C. C. Estratégias empresariais e formação de competências: um quebra-cabeça caleidoscópico da indústria brasileira. São Paulo: Atlas, 2000 .

Construindo o conceito de competência. Revista de Administração

Contemporânea (RAC). Rio de Janeiro, edição especial, p. 183-196, 2001.

FREITAS, H. et al. O método de pesquisa survey. Revista de Administração, São Paulo, v. 35, n. 3, p. 105-112, jul./set., 2000.

GUIMARÃES, T. A.; MEDEIROS, J. J. A nova administração pública e a gestão de competências: mudança e flexibilidade organizacional. In: Suzana M. V. Lima (Org.) Mudança organizacional. Teoria e gestão. Rio de Janeiro: FGV, 2003. cap. 8, p. 243-266.

GÜNTHER, H. Desenvolvimento de instrumento para levantamento de dados (survey). In: PASQUALI. L. (Org.). Teoria e métodos de medida em ciências do comportamento. Brasília: UnB-INEP, 1996. cap. 15, p. 387-403.

KILIMNIK, Z. M.; SANT’ANNA, A. S.; LUZ, T. R. Competências profissionais e modernidade organizacional: coerência ou contradição? Revista de Administração Eletrônica (RAE), São Paulo: EAESP/FGV, v. 4, n. 1, art. 1, jan./jun., 2005.

LE BOTERF, G. Desenvolvendo a competência dos profissionais. 3. ed., Porto Alegre: Artmed, 2003.

LEONARD-BARTON, D. Nascentes do saber: criando e sustentando as fontes de inovação. Rio de Janeiro: FGV, 1998. 
LOTTA, G. S. Avaliação de desempenho na área pública: perspectivas e propostas frente a dois casos práticos. Revista de Administração Eletrônica (RAE), São Paulo: EAESP/FGV, v. 1, n. 2, jul./dez., 2002.

LÜDKE, M. Métodos de coleta de dados: observação, entrevista e análise documental. In: LÜDKE, M.; ANDRÉ, M. L. Pesquisa em educação: abordagens qualitativas. 6. reimp., São Paulo: EPU, 1986. cap. 3, p. 25-44.

MARCONI, N. O fortalecimento das carreiras de Estado. In: PETRUCCI, Vera; SCHWARZ, Letícia (Org.). Administração pública gerencial: a reforma de 1995: ensaios sobre a reforma administrativa brasileira no limiar do século XXI. Brasília: Universidade de Brasília: ENAP, 1999. Parte III, p. 241-273.

MARRA, A. V.; MELO, M. C. O. L. A prática social de gerentes universitários em uma instituição pública. Revista de Administração Contemporânea (RAC). Rio de Janeiro, v. 9, n. 3, jul./set., p. 9-31, 2005.

MIRANDA, N. A. (Org.). Fundação Universidade de Brasília. Plano de desenvolvimento institucional (PDI-FUB) 2002-2006. Brasília: Universidade de Brasília, 2005.

MOURA, M. C. C.; BITENCOURT, C. C. A articulação entre estratégia e o desenvolvimento de competências gerenciais. Revista de Administração Eletrônica (RAE), São Paulo: EAESP/FGV, v. 5, n. 1, art. 3, jan./jul., 2006.

PACHECO, R. S. Proposta de reforma do aparelho do Estado no Brasil: novas idéias estão no lugar. In: PETRUCCI, V.; SCHWARZ, L. (Org.). Administração pública gerencial: a reforma de 1995: ensaios sobre a reforma administrativa brasileira no limiar do século XXI. Brasília: Universidade de Brasília: ENAP, 1999. Parte I, p. 97-122.

PERRENOUD, Philippe. Construir as competências desde a escola. Porto Alegre: Artes Médicas Sul, 1999.

Ensinar: agir na urgência, decidir na incerteza. Porto Alegre: Artmed, 2001.

PRAHALAD, C. K. Reexame de Competências. Revista HSM Management. São Paulo, v. 17, nov./dez., p. 40-46, 1999.

PRAHALAD, C. K.; HAMEL, G. Competindo pelo futuro. São Paulo: Elsevier, 2005.

RUAS, R. L. A atividade gerencial no século XXI e a transformação de gestores: alguns nexos pouco explorados. Revista Eletrônica de Administração (READ). Porto Alegre: UFRGS/EA/PPGA. Edição 15, v. 6, n. 3, out., 2000.

Desenvolvimento de competências gerenciais e contribuição da aprendizagem organizacional. In: FLEURY, M. T. L.; OLIVEIRA Jr., M. M. (Orgs.). Gestão estratégica do conhecimento. Integrando aprendizagem, conhecimento e competências. São Paulo: Atlas, 2001. p. 242-269. 
VERGARA, S. C. Começando a definir a metodologia. In: Projetos e relatórios de pesquisa em administração. 3. ed., São Paulo: Atlas, 2000. cap. 4, p. 46-53.

ZARIFIAN, P. A gestão da e pela competência. In: Seminário Educação Profissional, Trabalho e Competências. Rio de Janeiro: Centro internacional para a educação, trabalho e transferência de tecnologia, 1996. Mimeo.

Objetivo competência: por uma nova lógica. São Paulo: Atlas, 2001. 


\section{APÊNDICE A}

ROTEIRO DE ENTREVISTA - COMPETÊNCIAS GERENCIAIS

Função:

Nível:

Tempo na Função:

1. O que possibilita que você seja competente na sua atuação como gerente? 
2. O que permitiria que você se tornasse mais competente na sua atuação como gerente? 
3. Dentre as competências gerenciais abaixo relacionados, quais você considera fundamentais para um desempenho de excelência na sua atuação como gerente?

\begin{tabular}{|c|c|c|c|}
\hline Item & Competências gerenciais & $\mathbf{S}$ & $\mathbf{N}$ \\
\hline 1. & Conhecimento do Regimento Interno & & \\
\hline 2. & Conhecimento do Estatuto & & \\
\hline 3. & Conhecimento da legislação específica & & \\
\hline 4. & Aplicação da legislação específica & & \\
\hline 5. & Planejamento do trabalho & & \\
\hline 6. & Organização do trabalho & & \\
\hline 7. & Formação profissional compatível com a função & & \\
\hline 8. & Recursos disponíveis & & \\
\hline 9. & Julgamento & & \\
\hline 10. & Tomada de decisão & & \\
\hline 11. & Negociação & & \\
\hline 12. & Cumprimento dos prazos estabelecidos & & \\
\hline 13. & Conhecimento da missão e dos valores da instituição & & \\
\hline 14. & Conhecimento da estrutura organizacional & & \\
\hline 15. & Visão estratégica & & \\
\hline 16. & Conhecimento do Planejamento Estratégico da instituição & & \\
\hline 17. & Atualização acerca das novas tecnologias & & \\
\hline 18. & Conhecimento dos recursos da informática & & \\
\hline 19. & Aplicação dos conhecimentos dos recursos da informática & & \\
\hline 20. & Trabalho em equipe & & \\
\hline 21. & Absorção de conhecimentos & & \\
\hline 22. & Transferência de conhecimentos & & \\
\hline 23. & Relacionamento interpessoal & & \\
\hline 24. & Comunicação escrita & & \\
\hline 25. & Comunicação oral & & \\
\hline 26. & Criatividade & & \\
\hline 27. & Inovação & & \\
\hline 28. & Articulação interna & & \\
\hline 29. & Articulação externa & & \\
\hline 30. & Ética & & \\
\hline 31. & Discrição & & \\
\hline 32. & Visão sistêmica & & \\
\hline 33. & Elaboração de editais, portarias, relatórios diversos. & & \\
\hline 34. & Comprometimento com os interesses da instituição & & \\
\hline 35. & Conhecimento do orçamento público & & \\
\hline 36. & Aplicação dos conhecimentos sobre orçamento público & & \\
\hline
\end{tabular}




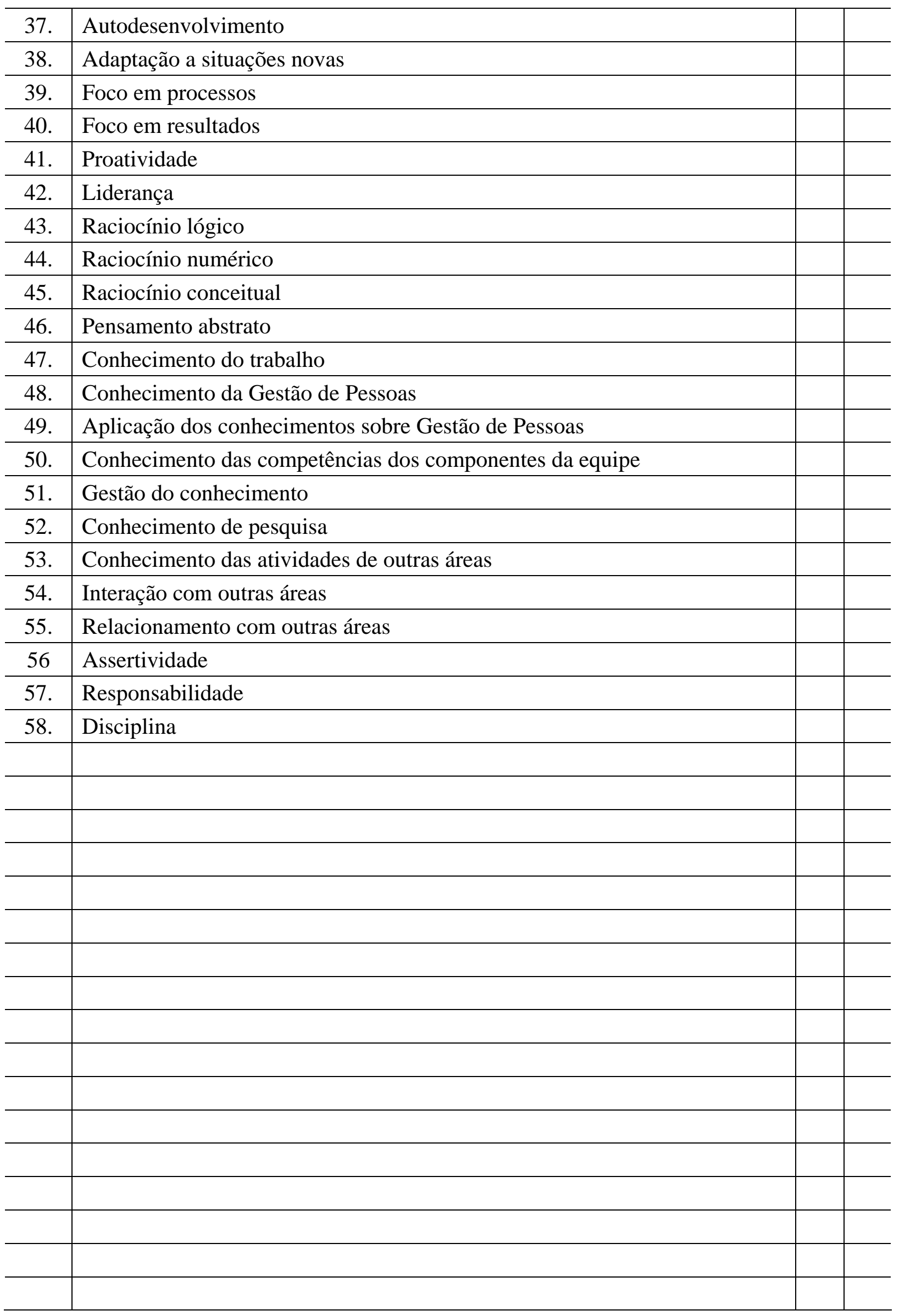

